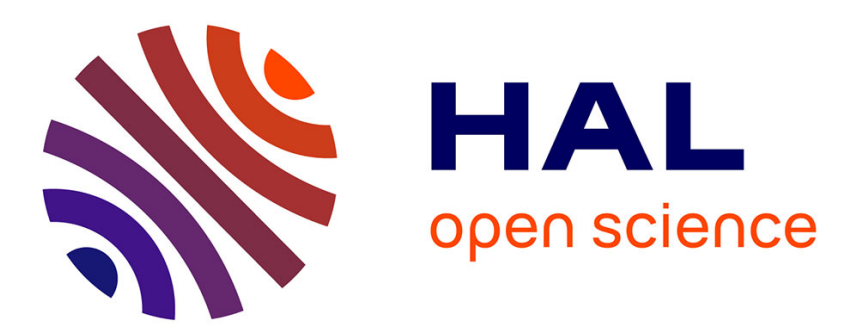

\title{
Molecular characterization of two sea bass gonadotropin receptors: cDNA cloning, expression analysis, and functional activity
}

Ana Rocha, Ana Gómez, Silvia Zanuy, José Miguel Cerdá-Reverter, Manuel Carrillo

\section{To cite this version:}

Ana Rocha, Ana Gómez, Silvia Zanuy, José Miguel Cerdá-Reverter, Manuel Carrillo. Molecular characterization of two sea bass gonadotropin receptors: cDNA cloning, expression analysis, and functional activity. Molecular and Cellular Endocrinology, 2007, 272 (1-2), pp.63. 10.1016/j.mce.2007.04.007 . hal-00531921

\section{HAL Id: hal-00531921 \\ https://hal.science/hal-00531921}

Submitted on 4 Nov 2010

HAL is a multi-disciplinary open access archive for the deposit and dissemination of scientific research documents, whether they are published or not. The documents may come from teaching and research institutions in France or abroad, or from public or private research centers.
L'archive ouverte pluridisciplinaire HAL, est destinée au dépôt et à la diffusion de documents scientifiques de niveau recherche, publiés ou non, émanant des établissements d'enseignement et de recherche français ou étrangers, des laboratoires publics ou privés. 


\section{Accepted Manuscript}

Title: Molecular characterization of two sea bass gonadotropin receptors: cDNA cloning, expression analysis, and functional activity

Authors: Ana Rocha, Ana Gómez, Silvia Zanuy, José Miguel Cerdá-Reverter, Manuel Carrillo

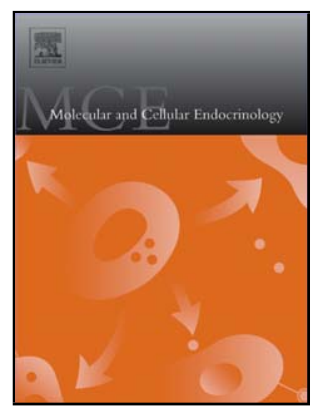

PII: S0303-7207(07)00160-8

DOI: doi:10.1016/j.mce.2007.04.007

Reference: MCE 6645

To appear in: $\quad$ Molecular and Cellular Endocrinology

Received date: $\quad 1-8-2006$

Revised date: $\quad$ 19-4-2007

Accepted date: $\quad$ 21-4-2007

Please cite this article as: Rocha, A., Gómez, A., Zanuy, S., Cerdá-Reverter, J.M., Carrillo, M., Molecular characterization of two sea bass gonadotropin receptors: cDNA cloning, expression analysis, and functional activity, Molecular and Cellular Endocrinology (2007), doi:10.1016/j.mce.2007.04.007

This is a PDF file of an unedited manuscript that has been accepted for publication. As a service to our customers we are providing this early version of the manuscript. The manuscript will undergo copyediting, typesetting, and review of the resulting proof before it is published in its final form. Please note that during the production process errors may be discovered which could affect the content, and all legal disclaimers that apply to the journal pertain. 


\section{Molecular characterization of two sea bass gonadotropin receptors: cDNA cloning, expression analysis, and functional activity.}

Ana Rocha, Ana Gómez*, Silvia Zanuy, José Miguel Cerdá-Reverter and Manuel Carrillo

Department of Fish Physiology and Biotechnology, Instituto de Acuicultura de Torre la Sal, Consejo Superior de Investigaciones Cientificas (CSIC), 12595 Torre la Sal, Ribera de Cabanes, Castellón, Spain.

*Address for correspondence: Ana Gómez

Instituto de Acuicultura de Torre la Sal.

Ribera de Cabanes s/n. 12595 Torre la Sal. Castellón. Spain.

Phone: +34 964 319500. Fax: +34964 319509

e-mail: ana@iats.csic.es 
Key words: Follicle-stimulating hormone; luteinizing hormone; G-protein coupled receptor; gonadal development; reproduction; teleost fish

\begin{abstract}
The follicle-stimulating hormone (FSH) and the luteinizing hormone (LH) play cen tral roles in vertebrate reproduction. They act through their cognate receptors to stimulate testicular and ovarian functions. The present study reports the cloning and characterization of two sea bass (Dicentrarchus labrax) cDNAs encoding a FSH receptor (sbsFSHR) and a LH receptor (sbsLHR). The mature protein s display typical features of the glycoprotein hormone receptor family members, but the sbsFSHR also contains some remarkable differences when compared with other fish or mammalian FSHRs. Among them, a distinct extracellular Nterminal cysteine domain as regards to its length and cysteine number, and the presence of an extra leucine-rich repeat. Expression analysis revealed that the $s b s F S H R$ is exclusively expressed in gonadal tissues, specifically in the follicular wall of previtelogenic and earlyvitelogenic follicles. On the contrary, $s b S L H R$ mRNA was found to be widely distributed in sea bass somatic tissues. When stably expressed in mammalian cell lines, sbsFSHR was specifically stimulated by bovine FSH, while sbsLHR was activated by both bovine LH and FSH. Nevertheless, specific stimulation of the sbsLHR was observed when recombinant sea bass gonadotropins were used. The isolation of a FSHR and a LHR in sea bass opens new ways to study gonadotropin action in this species.
\end{abstract}




\section{Introduction}

It is well established that the follicle-stimulating hormone (FSH) and the luteinizing hormone $(\mathrm{LH})$, secreted by the pituitary gland, play central roles in vertebrate reproduction (Chappel and Howles, 1991). In ovarian follicles, FSH regulates granulo sa cell proliferation, the synthesis of cell cycle-regulatory proteins and induces the expression of differentiationspecific genes (Richards, 1994). On the other hand LH promotes follicular maturation, ovulation and the synthes is of ovarian steroid hormones. In the testes, FSH determines Sertoli cell proliferation and attends germ cell maturation (Allan and Handelsman, 2005), while LH supports Leydig cell functions and stimulates the synthes is of androgens, regulating the final stages of spermatogenes is. FSH and LH are members of the glycoprotein hormone family, which also includes the thyroid stimu lating hormone (TSH) and the chorionic gonadotropin (CG) (Pierce and Parsons, 1981).

The glycoprotein hormones exert their biological actions by interacting with specific receptors present on target cell surfaces. Accordingly, the FSH receptor (FSHR) gene is expressed only in granulosa cells in the ovary and in Sertoli cells in the testis. The LH receptor (LHR) is expressed primarily in theca and granulosa cells of ovarian preovulatory follicles and in the Leydig cells in the testes (reviewed in refs. Themmen and Huhtaniemi, 2000; Ascoli et al., 2002; Vassart et al., 2004). In primates and equines, it also binds the CG, a placental hormone essential for the main tenance of pregnancy, structurally similar to LH (Bousfield et al., 1994). These receptors are encoded by paralogous genes belonging to the large family of G protein-coupled receptors (GPCRs) (Simoni et al., 1997; Ascoli et al., 2002; Dias et al., 2002; Szkudlinski et al., 2002), which includes in addition the TSH receptor that binds TSH. They constitute the subfamily of glycoprotein hormone receptors (GpHRs), themselves members of the wider leucine-rich repeat contain ing GPCR (LGR) family. The members of this family are characterized by a large extracellular (EC) domain with multiple 
imperfect leucine-rich repeats (LRRs), flanked by N- and C-terminal cysteine-rich subdomains. This is followed by a rhodopsin-like domain of seven transmembrane (7TM) helices and a C-terminal intracellular tail (Hsu et al., 2000).

Evidence for the presence of gonadotropin receptors in fish was first demonstrated more than ten years ago, by binding studies of coho salmon FSH and LH to membranes of isolated granulosa cells and theca-interstitial layers of coho salmon ovary (Yan et al., 1992; Miwa et al., 1994). The isolation of the cDNAs from these receptors remained elusive for years. Finally, the cloning of two types of gonadotropin receptors from the ovaries of amago salmon was reported (Oba et al., 1999a; Oba et al., 1999b), thereby providing new experimental tools to understand fish GpHRs biology.

Ligand binding and receptor activation appear to be distinct activities of the GpHRs. Ligand binding specificity and affinity are determined by residues present in the $\beta$-strands of the LRRs (Braun et al., 1991; Smits et al., 2003), whereas the TM domain is responsible for receptor activation and signal transduction through $\mathrm{G}$ proteins. Hormone binding to the $\mathrm{EC}$ domain of a GpHR causes changes in the 7TM domain promoting cAMP accumulation via activation of heterotrimeric Gs, thereby initiating a signalling cascade that leads to steroid synthesis (Ascoli et al., 2002; Dias et al., 2002; Szkud linski et al., 2002).

Ligand specificity of the mammalian GpHRs is well defined, with no cross-stimulation occurring under physiological conditions. Conversely, promiscuous activation of fish GpHRs has been described. In vitro experiments with African catfish, channel catfish and zebrafish recombinant FSHRs suggest that these are not selective for FSH, as LH can also activate them, whereas, LHRs are highly selective for homologous LH (Bogerd et al., 2001; Kumar et al., 2001a; Kumar et al., 2001b; Vischer and Bogerd, 2003; Kwok et al., 2005). These data are consistent with results obtained in coho salmon, whereby type I receptor (i.e., the putative FSHR), localized in both the theca and granulosa cells, did not discriminate between FSH and 
LH, while a type II receptor i.e., the putative LHR, located only in granulosa cells, was highly selective for LH (Yan et al., 1992; Miwa et al., 1994). However, the ligand selectivity of the amago salmon receptors appeared to be different from this (Oba et al., 1999a; Oba et al., 1999b). Heterologous cells transiently transfected with the amago salmon FSHR were specifically activated by chum salmon FSH but not by LH, whereas $L H R$ transfected cells were highly responsive to $\mathrm{LH}$ and in a lesser extend to $\mathrm{FSH}$.

This different ligand selectivity could imply that GpHR actions in teleosts are not totally overlapping those of their mammalian counterparts, and reinforces the need of learning more from fish, the most diverse group of vertebrates with dissimilar modes of gonadal development and reproductive strategies. Although the cloning of a FSHR and a LHR has been reported in two species of Percirforms, Nile tilapia and seabream (Oba et al., 2001; Wong et al., 2004), there is no information regarding the functional characterization of these receptors in this linage of fish.

To bring more knowledge on fish gonadotropin receptors, in the present study we report the isolation and functional characterization of the cDNAs coding for a sea bass FSHR ( $\operatorname{sbsFSHR)}$ and a LHR ( sbsLHR).

\section{Materials and Methods}

\section{Isolation of Nucleic Acids}

Sexually mature female and male sea bass (Dicentrarchus labrax) were obtained from the stock raised in the Instituto de Acuicultura de Torre la Sal facilities. Animals were treated in accordance with the European Union Animal Care Regulations.

Total RNA was isolated from sea bass tissues ( $n=2$ animals/ tissue) following the TRI Reagent protocol (Molecular Research Center, Inc. Cincinnati, OH). Poly (A) ${ }^{+}$RNA was isolated using PolyATtract mRNA Isolation Systems (Promega Corp., Southampton, UK). 
Genomic DNA (gDNA) was isolated from sea bass whole blood, using a protein salting-out method (Martín ez et al., 1998).

\section{Reverse transcription-Polymerase Chain Reaction (RT-PCR) and Polymerase Chain Reaction}

To perform PCR amplification on sea bass gDNA $150 \mathrm{ng}$ were used as template. Supers cript II reverse transcriptase (Invitrogen Corp., Carlsbad, CA) was used for cDNA synthesis by priming $4 \mu \mathrm{g}$ of RQ1-DNase (Promega Corp.) treated total RNA with 100 ng of random hexamers in a total volume of $20 \mu \mathrm{l}$. Briefly, RNA was mixed with $100 \mathrm{ng}$ of random hexamers, $1 \mu \mathrm{l}$ of dNTPs $(10 \mathrm{mM}$ each dNTP $)$ and denatured at $65^{\circ} \mathrm{C}$ for $5 \mathrm{~min}$. After a quick chilling on ice, 40 units of RNAsin (Promega Corp.), and 200 units of SuperScript II reverse transcriptase were added. Incubation took place at $42^{\circ} \mathrm{C}$ for $50 \mathrm{~min}$. The reaction was stopped by heating to $70^{\circ} \mathrm{C}$ for $15 \mathrm{~min}$.

One to $2.5 \mu 1$ of the cDNA were used for PCR reactions. The sequences of the primers used in this study are shown in Table 1 . Touchdown PCR programs comprising a 10 to $15^{\circ} \mathrm{C}$ span of annealing temperatures were used following these conditions: an initial denaturation at $94^{\circ} \mathrm{C}$ for $2 \mathrm{~min}$ followed by $30\left(15^{\circ} \mathrm{C}\right.$ span $)$ or $20\left(10^{\circ} \mathrm{C}\right.$ span $)$ cycles of $94^{\circ} \mathrm{C}$ for $30 \mathrm{~s}$, the highest annealing temperature for $30 \mathrm{~s}$, and $72^{\circ} \mathrm{C}$ for $45 \mathrm{~s}$. The annealing temperature was decreased $0.5^{\circ} \mathrm{C}$ per cycle.

Primer pairs fshr25-fshr26 and lhr35-lhr23 (Table 1) were designed to amplify an intron-contain ing region in order to exclude false positive bands arising from potential contaminating gDNA. Also, they share limited sequence identity. As internal control a $495 \mathrm{bp}$ fragment of the sea bass $18 \mathrm{~S}$ ribosomal RNA (rRNA) gene was amplified, using primers 5'18S and 3'18S . Cycling conditions consisted of 25 cycles at $94^{\circ} \mathrm{C}$ for $30 \mathrm{~s}, 65^{\circ} \mathrm{C}$ for $45 \mathrm{~s}$, and $72^{\circ} \mathrm{C}$ for $45 \mathrm{~s}$. 
The resulting PCR products were cloned into the pGEM-T Easy Vector (Promega Corp.) and sequenced.

\section{Screening of a sea bass cDNA testic ular library}

A 1175 bp cDNA fragment from the $s b s F H R$ and a $678 \mathrm{bp}$ cDNA fragment of the sbsLHR were labelled with $\left[\alpha-{ }^{32} \mathrm{P}\right]$-dCTP by random octamer priming (Rad Prime DNA Labelling System Kit, Invitrogen Corp.) and used as probes to screen, following standard methods (Sambrook \& Russel 2001), a sea bass testicular directional cDNA library constructed in the UNI-ZAP XR vector.

Prehybridizations and hybridizations were done at high stringency conditions (50\% formamide, $42^{\circ} \mathrm{C}$ ). Final washes were carried out at $55^{\circ} \mathrm{C}$ with $1 \mathrm{xSSPE}$ and $0.5 \%$ SDS. Several positive clones were obtained after first round screening of approximately $1 \times 10^{6}$ phages. Secondary and tertiary screenings were performed and the resulting positive phages were in vivo excised from the Lambda ZAP XR vector as pBluescript SK (-) phagemids, following the protocol described by the manufacturer (Stratagene Corp.).

\section{DNA Sequence and Phylogenetic analys is}

DNA sequences were determined for both strands on an automated ABI PRISM 3730 DNA Analyser (Applied Byosistems) using the Rhodamine Terminator Cycle Sequencing Kit (Perkin-Elmer Inc., Wellesley, MS). The generated sequences were assembled using Sequencher version 4.0.5 software (Gene Codes Corpor., Ann Arbor, MI). BLASTN and BLASTP (version 2.2.9, National Center for Biotechnology Information) were used for database searching. The presence and location of the putative signal peptide cleavage site, the 7TM helices, Ser, Thr, and Tyr phosphorylation sites and potential N-glycolylation sites in the amino acid sequences, were predicted using the prediction servers of the Center for Biological 
Sequence Analysis (http://www.cbs.dtu.dk/services/). The Protein Families (Pfam) Database of the Sanger Institute (UK) was used to search for common protein domains. The UniProt name for the sbsFSHR and the sbsLHR are Q4L192_DICLA and Q4L191_DICLA respectively. Multiple sequence alignments were carried out using ClustalX version 1.81 (Thompson et al., 1997). Phylogenetic analyses, of full length amino acid sequences, were conducted using MEGA version 2.0 (Kumar et al., 2001). A rooted phylogenetic tree was constructed by means of the Neighbor-joining algorithm, using the LGR sequence of Caenorhabditis elegans as an outgroup. Gaps or missing data were pairwise deleted. One thousand bootstrapping pseudo replicates were used to assess the robustness of the inferred nodes of the tree.

\section{Northern blot analys is}

Poly $(\mathrm{A})^{+}$RNA $(10 \mu \mathrm{g})$ from sea bass ovaries and total RNA $(30 \mu \mathrm{g})$ from testes and ovaries were denatured and electrophoresed in the presence of formaldehyde using standard conditions (Sambrook and Russel, 2001). RNAs were blotted on a Hybond-NX nylon membrane (Amersham Biosciences UK Ltd.) and stained with methylene blue to control for equal loading. Prehybridization and hybridization were carried out overnight at $42^{\circ} \mathrm{C}$ with $50 \%$ formamide. The full length $s b s F S H R$ and $s b s L H R$ cDNAs were labelled with $\left[\alpha-{ }^{32} \mathrm{P}\right]-$ $\mathrm{dCTP}$ and used as probes. Finalwashes were performed in $2 \mathrm{xSSC} / 0.5 \% \mathrm{SDS}$ at $50^{\circ} \mathrm{C}$. The membranes were exposed to Hyperfilm ${ }^{\mathrm{TM}}$ MP autoradiography films (Amersham Biosciences UK Ltd.).

\section{In situ hybridization}

In situ hybrid ization experiments were carried out as described previously (CerdaReverter et al., 2003). Briefly, sea bass gonads were fixed with 4\% paraformaldehyde (PAF) 
overnight at $4^{\circ} \mathrm{C}$, dehydrated, and embedded in Paraplast (Sherwood, St. Louis, MO). Before hybridization, $6 \mu \mathrm{m}$ sections were deparaffinized, rehydrated, and postfixed. Slides were later washed in phosphate buffer (PB) and treated with Proteinase-K. Next, they were washed in $\mathrm{PB}$ and post fixed again in PAF, subsequently rinsed in sterile water, and acetylated in a triethanolamine $(0.1 \mathrm{M}, \mathrm{pH} 8)$ /acetic anhydride solution. Sections were then dehydrated and dried at room temperature.

A pBluescript SK (-) phagemid containing an 800 bp fragment from the $s b s F S H R$ 3' UTR was used to prepare riboprobes. Antisense and sense RNA probes were synthesized in vitro by linearizing the phagemid with $X b a \mathrm{I}$ or $X h o \mathrm{I}$, and in vitro transcription was carried out with T7 or T3 RNA polymerase, respectively. The probes were labelled with ${ }^{35} \mathrm{~S}-\mathrm{UTP}$ using the Riboprobe In Vitro Transcription System Kit (Promega Corp.). After in vitro RNA synthesis, samples were treated with $1 \mathrm{U}$ of RQ1-DNase RNAse-free (Promega Corp.) and purified on Sephadex G50 columns. The two fractions containing the highest radioactivity were pooled, precipitated, stored at $-20^{\circ} \mathrm{C}$ and used within 1 week.

The ${ }^{35} \mathrm{~S}-\mathrm{UTP}$ riboprobes were pelleted and dissolved in an appropriate volume of 100 mM DTT to obtain $2 \times 10^{5} \mathrm{cpm} / \mu 1$. After 5 minutes incubation at $80^{\circ} \mathrm{C},{ }^{35} \mathrm{~S}-\mathrm{UTP}$ riboprobes were diluted 1/10 (final concentration of probes, $10 \mathrm{mM} \mathrm{DTT}$ and $2 \times 10^{4} \mathrm{cpm} / \mu \mathrm{l}$ ) in hybridization buffer containing 50\% formamide, $300 \mathrm{mM} \mathrm{NaCl}, 20 \mathrm{mM}$ Tris- $\mathrm{HCl}(\mathrm{pH} 8), 5$ mM EDTA (pH 8), 10\% Dextan sulphate, 1X Denhardt's solution and $0.5 \mu \mathrm{g} / \mathrm{ml}$ of yeast RNA type III. Subsequently, $60 \mu 1$ of hybridization solution were added to each pre-treated slides (see above) that were cover-slipped and incubated in a humidified chamber overnight at $55^{\circ} \mathrm{C}$.

After washing and ribonuclease treatment, slides were finally dehydrated and dried at room temperature. Finished the hybridization process, slides were dipped in Hypercoat Photographic Emulsion RPN40 (Amersham Biosciences UK Ltd) and exposed under dry 
conditions at $4^{\circ} \mathrm{C}$ for 15-20 days, developed in Kodak D-19 Film Developer and counterstained with Cleveland \& Wolfe staining (Herlaut 1960). Anatomical locations were confirmed by reference to Mayer et al. (1990) and Alvariño et al. (1992).

\section{Expression plasmids, cell culture and transfections}

The pcDNA-sbsFSHR plasmid was generated by inserting a $2.8 \mathrm{~kb}$ fragment containing the complete open reading frame (ORF) of the $s b s F S H R$ into the pcDNA3 expression vector (Invitrogen Corp.). The expression vector pcDNA-sbsLHR, containing the complete ORF of the $s b s L H R$ was generated in several steps. First, two fragments corresponding to the EC domain of $s b s L H R$ were PCR amplified with primer pairs $1 \mathrm{hr} 30$ lhr24 and $1 \mathrm{hr} 35-\mathrm{lhr} 21$ respectively (Table 1). Equal quantities of each fragment were used as template in an overlapping PCR reaction with primers $1 \mathrm{hr} 30-\mathrm{hhr} 21$ (Table 1). The resulting PCR product was inserted into the pPCR-Script Amp SK $(+)$ cloning vector (PCR-Script ${ }^{\circledR}$ Amp Cloning Kit, Stratagene, La Jolla, CA). A HindIII-VspI fragment from this plasmid containing most of the EC domain (nucleotides 1 to 1048) was in-frame ligated to a VspIEcoRV fragment (nucleotides 1048 to 3172) obtained from a cDNA library phagemid, which corresponds to the rest of the $s b s L H R$ cDNA. Finally, they were introduced into the HindIIIEcoRV-digested pcDNA3 vector (Invitrogen Corp.). All the above PCR reactions were performed with the proofreading $P f u T u r b o \circledR$ DNA polymerase (Stratagene, La Jolla, CA) and further checked by sequencing. pCRE-luc (BD Clontech, Palo Alto, CA) contains the firefly luciferase gene under the con trol of a promoter with cAMP Responsive Elements (CRE) binding sites. The tgCMV/HyTK plasmid harbours a hygromycin resistance gene (Wellbrock et al., 1998).

Human embryonic kidney (HEK) 293 cells were grown in DMEM (Invitrogen Corp) contain ing $10 \%$ foetal bovine serum, penicillin (100 units $/ \mathrm{ml})$ and streptomycin $(100 \mu \mathrm{g} / \mathrm{ml})$ 
in a humidified atmosphere of $5 \% \mathrm{CO}_{2}$ at $37^{\circ} \mathrm{C}$. Cells were transfected using a modified calcium phosphate transfection method (Chen and Okayama, 1987) or Lipofectamine 2000 reagent according to manufacturer's guidelines. pcDNA-sbsFSHR and tgCMV/HyTK were co-transfected (50:1) in cells growing in 24-well plates. pcDNA-sbsLHR, pCRE-luc and $\operatorname{tgCMV/HyTK}$ were co-transfected (50:50:1) in cells growing in 6 well culture plates. To generate stable clones, 48 hours after transfection cells were replated in 96-well plates and selected in medium containing $400 \mu \mathrm{g} / \mathrm{ml}$ of hygromycin B (Invitrogen). Hygromycin resistant colonies were isolated 2 weeks after transfection and subsequently expanded. In the sbsFSHR stable clones, the expression level of this gene was analyzed by Northern blot. Transient transfections of the pCRE-luc plasmid were performed in $9 \mathrm{~cm}$ dishes. Forty eight hours after transfection, cells were spread in 24-well plates and stimulated by adding the specified amounts of hormones in the growth medium for the indicated times.

The sbsLHR single clones were screened for luciferase activity by treating the cells with $100 \mu \mathrm{M}$ forskolin (Sigma-Aldrich Co.) for five hours. Untreated cells were used as controls. The clone presenting the highest difference in luciferase activity between treated and untreated cells (LHR-LUC10) was further expanded. For functional characterization of the sbsLHR, LHR-LUC10 cells were spread in 48 well plates and stimulated by adding the specified amounts of hormones on the growth medium for five hours.

Bovine FSH (bFSH, AFP-5332B, biopo tency 68 x NIH-FSH-S1) and bovine LH (bLH, AFP-11743B, biopotency 2,3 x NIH-LH-S1) were obtained from the National Hormone \& Peptide Program, Harbor-UCLA Medical Center (California, USA). Cells were also challenged with conditioned medium of cultured Chinese hamster ovary (CHO-K1) stable clones producing recombinant sea bass LH and FSH (Gómez et al., unpublished). 


\section{Luciferase assay}

To measure luciferase activity, cells were lysed in Reporter Lysis Buffer (Promega Corp.) as indicated by the manufacturer. Cell debris were separated by centrifugation for $30 \mathrm{~s}$ at $15000 \mathrm{xg}$, and $20 \mu \mathrm{l}$ of the supernatant were mixed with $200 \mu \mathrm{l}$ of luciferin reagent $(20 \mathrm{mM}$ TricineKOH, pH 7.8, 0.1 mM EDTA, $8 \mathrm{mM} \mathrm{MgCl}_{2}, 33.3 \mathrm{mM}$ DTT, $270 \mu \mathrm{M} \mathrm{CoA}, 530 \mu \mathrm{M}$ ATP, $400 \mu \mathrm{M}$ luciferin). The light emitted was measured in a luminometer (Junior, EG\&G, Berthold) and expressed as relative light units (RLU).

\section{Results}

\section{Cloning and sequence analys is of a sbsFSHR and a sbsLHR cDNAs}

Two pairs of degenerate oligonucleotides (fshr6-fshr2 and fshr1-fshr2) were designed based on published fish and mammalian FSHR and LHR sequences respectively, and corresponding to a highly conserved and intronless region of the TM domain. They were used as primers in a PCR reaction using sea bass gDNA as template. A $330 \mathrm{bp}$ and a $680 \mathrm{bp}$ products were amplified, and subsequently subcloned and sequenced. The obtained sequences displayed the highest identity to other FSHRs and LHRs respectively. A $s b s F S H R$ specific primer (fshr9), based on the sequence of the amplified product, was used in a PCR reaction on testis cDNA in combination with a degenerated primer designed on the EC domain (fshr8).

The amplified fragment was about $1.1 \mathrm{~Kb}$. Screenings of a cDNA testicular library using the sbsFHSR $1.1 \mathrm{~Kb}$ and the $s b s L H R 680 \mathrm{bp}$ fragments as probes rendered a high number of positive clones for the $s b s F S H R$ and a single specific clone for the $s b s L H R$.

The sbsFSHR sequence. PCR and sequencing analysis of the 5' region of the sbsFSHR clones showed that eight of them were full length and contained the ATG initiation codon. One of them was chosen for in vivo excision and sequencing. This phagemid contained a 3134 bp fragment (Fig. 1), consisting of an ORF of 2109 nucleotides that was flanked by 
leader and trailer sequences of 206 and 819 nucleotides respectively. This ORF encodes a protein of 702 amino acids of which the first 20 amino acids were predicted to constitute the putative signal peptide (Fig. 1). The mature protein displayed typical features of members of the GpHR family. The predicted EC domain contains 377 amino acids, including the signal peptide, followed by a putative 7TM domain and an intracellular C-terminal domain.

The sbsFSHR protein showed the highest identity with FSHRs of other fish species (81\%-53\%), followed by mammalian FSHRs (46\%-45\%), chicken FSHR (45\%), mammalian LHRs (44\%-43\%), chicken LHR (41\%), fish LHRs (41\%-38\%), reptile FSHRs (47\%-46\%) and fish and mammalian TSHRs (39\%-35\%). Amino acid sequence alignment of the sbsFSHR with other glycoprotein receptors, made clear that the most conserved regions of the receptor are the TM domain and the intracellular loop between TM I and TM II, whereas the least conserved areas are the EC domain (Fig. 2) and the intracellular loop between TM V and TM VI. The ClustalX alignment also revealed the presence of specific signature sequences (e.g. ${ }^{316} \mathrm{CCAF},{ }^{364} \mathrm{FNPCED},{ }^{477} \mathrm{ERW},{ }^{590} \mathrm{FTD},{ }^{634} \mathrm{NPFLY}$ ), highly conserved in GpHRs (Vassart et al., 2004) (Fig. 2).

When aligning the amino acid sequence of the sbsFSHR with other fish and human FSHR sequences, two insertions and one deletion were identified in the EC domain of the sbsFSHR (Fig. 2). The first insertion, of 9 amino acids, is placed just after the signal peptide. The second one, considerable larger ( 25 amino acids), begins in amino acid position 80 . Finally, a 30 amino acid deletion, with respect to the human FSHR (hFSHR), is easily identified in the $\mathrm{C}$-terminal region of the $\mathrm{EC}$ domain, in the middle of the cysteine-rich cluster. This deletion is present in other fish FSHRs.

Predictions for $\mathrm{N}$-glycosylation sites identified five motifs in the sbsFSHR at positions ${ }^{62} \mathrm{NTT},{ }^{232} \mathrm{NGT},{ }^{309} \mathrm{NLT},{ }^{325} \mathrm{NRS}$ and ${ }^{351} \mathrm{NST}$ (Fig. 1). In other fish species, these potential 
sites are also present, but only the first two are conserved in the hFSHR (Fig. 2) (Davis et al., 1995).

Pfam database searching and further comparison with the hFSHR allowed the identification of 10 imperfect LRRs in the sbsFSHR, with lengths ranging from 22 to 25 residues. One of these repeats is within the 25 -amino acid insertion mention ed above, and thus would correspond to an additional LRR (Fig. 1 and 2). In the areas flanking the LRR region, two $\left(\mathrm{Cys}^{45}\right.$ and $\mathrm{Cys}^{65}$ ) and six cysteines (Cys at positions 316, 317, 333, 349, 357 and 367) exist in the sbsFSHR, which could represent the $\mathrm{N}$ - and C-terminal cysteine-rich clusters respectively.

The TM domain of the sbsFSHR cons is ts of 263 amino acids, and includes seven stretches of 21-23 predominantly hydrophobic residues predicted to form $\alpha$-helices and connected by three intracellular and three EC loops (Fig. 1). The first and second EC loops of this domain contain two highly conserved cysteines $\left(\mathrm{Cys}^{453}\right.$ and $\mathrm{Cys}^{528}$ ), predicted to form an intramolecular disulfide bound, which constrains the protein (Gudermann et al., 1995). The conserved ERW motif can be found at the bottom of the predicted TM III, and contains Arg ${ }^{478}$ and $\mathrm{Glu}^{477}$, that would form an ionic lock with $\mathrm{Asp}^{578}$ at the cytoplasmic end of the TM VI. Activation of the receptor involves the disruption of this ionic look, which causes a crucial movement of these two $\alpha$-helices. The NPxxY motif is also present, and includes $\mathrm{Asn}^{633}$ one of the most conserved residues in rodopsin-like GPCRs. It has been suggested that this residue would be implicated in the activation mechanism by switching its interaction between two aspartic residues, both existing in the sbsFSHR (Asp ${ }^{592}$ and Asp ${ }^{419}$ ) (Vassart et al., 2004). Phosphorylation site predictions identified two potential phosphorylation sites, $\mathrm{Thr}^{566}$ and $\mathrm{Ser}^{571}$, in the third intracellular loop and 5 potential phosphorylation sites, $\mathrm{Thr}^{643}, \mathrm{Ser}^{669}$, $\operatorname{Ser}^{671}, \operatorname{Ser}^{679}$ and $\mathrm{Ser}^{683}$, in the intracellular C-terminal domain. From them, $\mathrm{Thr}^{566}$ and $\mathrm{Thr}^{643}$ 
are potencial phosphorylation sites for protein kinase C, while $\operatorname{Ser}^{571}$ and $\operatorname{Ser}^{683}$ are potential sites for protein kinase A phosphorylation.

The $s b s L H R$ sequence. The single isolated clone for the $s b s L H R$ contained a cDNA insert of $2228 \mathrm{bp}$. Sequence analysis revealed that this clone did not contain the full length sbsLHR cDNA, as it was lacking coding sequence at its 5' end. Based on information obtained from the genomic sequence of the $s b S L H R$ (unpublished data), a specific primer (lhr30) annealing to the 5' UTR of $s b s L H R$ gene was designed. It was used for PCR amplification of testis cDNA in order to obtain the remaining $s b s L H R$ cDNA sequence. The combination of this PCR product plus the cDNA sequence obtained from the library yield a sbsLHR cDNA sequence of $3172 \mathrm{bp}$. It consists of an ORF of $2166 \mathrm{bp}$ that codes for a 721 amino acid polypeptide, flanked by 5' UTR and 3' UTR of 158 bp and 848 bp, respectively. The first 21 amino acids were predicted to constitute the putative signal peptide. The complete nucleotide and deduced amino acid sequence are shown in Fig. 3. sbsLHR contains all the features of a GpHR. The large EC amino-terminal domain consists of 388 amino acids, including the signal peptide. Searches in the Pfam database and alignments with other GpHRs allowed us to identify, within this domain, nine imperfect LRRs, with sizes raging from 21 to 25 amino acids each. These LRRs are flanked by ten conserved cysteines, four of them in an $\mathrm{N}$-terminal cluster (Cys at positions 27, 31, 33 and 40) and six in a C-terminal group (Cys at positions 283, 284, 308, 360, 368 and 378). The predicted TM domain, of 261 amino acids, includes 7 stretch es of hydrophobic residues. The intracellular C-terminal domain consists of 72 amino acids and has two highly conserved contiguous cysteines ( $\mathrm{Cys}^{668}$ and $\mathrm{Cys}^{669}$ ). Three $\mathrm{N}$-glycosylation motifs were identified in the sbsLHR EC domain at positions ${ }^{42} \mathrm{NVT},{ }^{103} \mathrm{NLS}$, and ${ }^{199}$ NGT (Fig. 3). Only two of them, the second and third, are conserved between mammalian and sea bass LHRs. (Vu-Hai et al., 2000). NetPhosK 1.0 prediction server found one site, $\mathrm{Thr}^{590}$, in the third intracellular loop of the TM, and six sites, $\mathrm{Thr}^{652}, \mathrm{Ser}^{671}, \mathrm{Ser}^{674}$, 
$\mathrm{Ser}^{683}, \mathrm{Ser}^{693}$ and $\mathrm{Ser}^{711}$ in the intracellular C-terminal domain of the sbsLHR, predicted to be phosphorylated by protein kinase $\mathrm{C}$.

The sbsLHR protein has the highest identity to LHRs of other fish species $(86 \%$ 45.5\%), followed by chicken LHR (51\%), mammalian LHRs (49\%-48\%), mammalian FSHRs (46\%-45\%), reptile FSHRs (44.5\%-38\%), fish FSHRs (43.5\%-37\%) and mammalian and fish TSHRs (41\%-37\%). Sea bass FSHR and LHR EC domains are 28\% identical, while their TM and intracellular domains are $64 \%$ identical. The overall amino acid identity between these two sea bass proteins is $41 \%$. Alignment of the sbsLHR amino acid sequence with other LHRs, showed that the most divergent areas are the C-terminus of the EC domain and the intracellular domain (data not shown). Similarly to the sbsFSHR, highly conserved GpHR signature sequences (e.g. ${ }^{375}$ FNPCEDIMSA, ${ }^{488}$ ERW, ${ }^{601}$ FTD, ${ }^{644}$ NPFLY) (Vassart et al., 2004) were also found in the sbsLHR.

\section{Phylogenetic analys is}

The evolutionary relationship of the $s b s F S H R$ and $s b s L H R$ to other members of the GpHR family was inferred by performing a phylogenetic analysis by the Neighbour-joining method. The topology of the resulting rooted tree (Fig. 4) shows three main groups: LHR, FSHR and TSHR lineages. The LHRs are separated from the other GpHRs in $73 \%$ of the replicates while the FSHR and TSHR clades presented a bootstrap value of 78. As predicted by fish evolutionary relationships (Nelson, 1994), $s b s F S H R$ and $s b S L H R$ sequences exhibit the closest relation with the seabream gonadotropin receptors.

\section{Expression analys is}

The tis sue expression pattern of the $s b s F S H R$ and $s b s L H R$ was analyzed by RT-PCR (Fig. 5A, B). sbsFSHR mRNA was only detected in gonads, and higher levels were seen in 
testis compared to the ones observed in ovary. No transcrip ts were amplified in the somatic tissues analyzed (Fig. 5A). On the o ther hand, the $s b s L H R$ showed the highest expression in gonadal tissues, but lower expression levels were detected in different somatic tissues, from which the head and ventral kidneys as well as the spleen presented the strongest amplification signal (Fig. 5B). Sequencing results from two randomly selected RT-PCR products (liver and gills) confirmed the authenticity of these extragonadal amplicons (Fig. 5B).

Northern blot analysis of poly (A) ${ }^{+}$RNA and total RNA from sea bass gonads, using the full length $s b S F S H R$ cDNA as a probe, revealed two faint hybridization signals corresponding to two different transcripts. One of approximately $3 \mathrm{~kb}$, which corresponds to the full length mRNA and ano ther of $1.8 \mathrm{~kb}$ that would be consistent with the existence of an alternatively spliced $s b s F S H R$ transcript (Fig. 5C). When the $s b s L H R$ cDNA was used as a probe, a faint and diffu se hybridization signal, of approximately $3 \mathrm{~kb}$, was detected; this could contain $s b s L H R$ tran scripts slightly different in size (Fig. 5C). No signal could be detected in Northern blot when to tal RNA was used (data not shown). The level of expression obtain for both receptors in the Northern blot analysis, indicates that the $s b s L H R$ is expressed to a much lower level than the $s b s F S H R$.

To establish the cellular localisation and maturation stage dependent expression of the sbsFSHR, we carried out an in situ hybridization on ovary sections of mature sea bass female. When an antisense probe was used, a strong expression was observed in previtelogenetic oocytes (Fig. 6A). Positive signals were also detected in the follicular cells of oocytes in early and late stages of the vitelogenesis process (Fig. 6B, C, D). Little or no expression was found in mature oocytes. No specific signal was gen erated with a $s b S F H R$-cRNA sense probe (data not shown). 


\section{Activation of the sbsFSHR and sbsLHR by gonadotropins}

To test the functionality of the isolated sbsFSHR and sbsLHR we expressed their cDNAs in HEK293 cells. It has been described (Tao et al., 2000) that the expression of a high number of gonadotropin receptors per cell can result in an increase in the basal level of activation of the receptor. With the aim of obtaining low amounts of receptor expressed per cell we developed stable HEK293 clones containing the $s b s F S H R$ or the $s b s L H R$ cDNAs. In the case of the $s b S F S H R$ we analyzed those clones by Northern blot (data not shown) and selected the one that rendered the lowest expression of the receptor. On this clone we performed transient transfections with the pCRE-luc plasmid. To assess the functionality of the sbsLHR, we developed stable transfected HEK293 cells expressing the $s b s L H R$ and the luciferase based reporter construct pCRE-luc (LHR-LUC10 cells). The activation of gonadotropin receptors results in the activation of the cAMP pathway (reviewed in Means et al., 1980) what finally leads to the expression of gen es containing CRE binding sites in their promoters. Thus, the increase in luciferase activity as a result of its expression from the pCRE-luc plasmid constitutes an indirect measurement of the increase in intracellular cAMP.

The sbsFSHR/pCRE-luc double transfectants were stimulated with different amounts $(0-5 \mu \mathrm{g} / \mathrm{ml})$ of bFSH and bLH. When stimulated with bFSH we observed that the luciferase activity increased following a dose-response curve, while those cells treated with bLH did not show an increase in luciferase activity different from the untreated cells, even at high concentration ( $5 \mu \mathrm{g} / \mathrm{ml})$ (Fig. 7B). In a time course experiment we show that maximum luciferase activity is obtained 6 hours after bFSH stimulation and no increase in luciferase activity is obtained in those cells treated with bLH (Fig. 7A). All together these data show that the sbsFSHR is specifically stimulated by FSH but not by LH.

LHR-LUC10 cells were stimulated with different amounts $(0-5 \mu \mathrm{g} / \mathrm{ml})$ of bLH and bFSH. Treatment with bLH increased luciferase activity in a clear dose-dependent manner. 
Interestingly, bFSH was also effective in stimulating the sbsLHR in a similar way as the one observed for the bLH, with luciferase activity being only slightly lower (Fig. 8A). On the contrary, when LHR-LUC10 cells were stimulated with condition ed medium from CHO-K1 stable clones producing recombinant sbsFSH, no increase in intracellular cAMP was observed compared to the cells treated with $\mathrm{CHO}-\mathrm{K} 1$ wild type medium. (Fig. 8B). On the other hand, conditioned medium of CHO-K1 stable clones producing recombinant sbsLH was effective in stimulating the sbsLHR (Fig. 8B).

\section{Discussion}

This study describes the cloning of two sea bass cDNAs that code for a FSHR and a LHR. They contain all the general structural features of a GpHR, but important differences were observed in the sbsF SHR. Unlike hFSHR, sbsLHR and many other LRR-containing proteins that have four cysteines in their N-terminal cysteine-rich region, the sbsFSHR has only two cysteines ( $\mathrm{Cys}^{45}$ and $\left.\mathrm{Cys}^{65}\right)$. This allows the formation of a single disulphide bridge in the sbsFSHR with a different location than the two bridges found in the hFSHR (Fan and Hendrickson, 2005), what suggests a different fold ing for each receptor in this region. In other fish FSHRs the number of cysteines in this region is variable (Fig 2). Besides, the sbsFSHR, as well as Nile tilapia and seabream FSHRs, have an insertion of nine amino acids in th is domain, precisely where one of the two cysteines is found (Fig. 2).

The N-terminal region is followed by the LRR domain. LRRs are usually involved in protein-protein interactions, and are constituted of $\beta$-strand/ $\alpha$-helix units connected by a turn and arranged in a horseshoe-like configuration (Kobe \& Kajava 2001). We identified nine LRR motifs in the sbsLHR, which match with the nine LRRs described for the hLHR. In the sbsFSHR ten LRRs were identified, nine of them correspond with repeats of the hFSHR, and the additional one is encoded by the 25 -amino acid insertion described previously (Fig. 2). 
The presence of this extra LRR indicates that the binding domain of the sbsFSHR could have a distinct curv ature and size, influencing hormone recognition.

The crystal structure of the human FSH (hFSH) in complex with a fragment of the hFSHR EC domain $\left(\mathrm{hFSHR}_{1-250}\right)$ has revealed how the hFSH- $\alpha$ and $-\beta$ subunits bind the receptor making contacts with all the $\beta$-strands of the LRRs (Fan and Hendrickson, 2005). From the residues buried at the receptor/ligand interface either by one subunit alone or by both hFSH- $\alpha$ and $-\beta$, few are conserved in the sbsFSHR. A higher preservation is found in sbsFSHR LRR5 (amino acids 163 to 171 ) that is predicted to interact mostly with FSH- $\alpha$ residues. A key feature in this area is an aromatic ring interaction between $\mathrm{Tyr}^{88}$ of hFSH- $\alpha$ and $\mathrm{Tyr}^{124}$ of hFSHR, which correspond to $\mathrm{Tyr}^{90}$ and $\mathrm{Tyr}^{164}$ in their sea bass counterparts. In addition, Asn ${ }^{129}$ and Gly ${ }^{131}$ make important contacts with different residues in the $\alpha$-subunit, and both are conserved in sbsFSHR ( Asn $^{169}$ and Gly ${ }^{171}$ ).

Although collective interfaces may contribute to the specificity of binding, three potential determinants of specificity have been identified in the hFSHR (Fan and Hendrickson, 2005), namely residues Leu ${ }^{55}$, Lys ${ }^{179}$ and the combination of $\mathrm{Glu}^{76}$ and $\mathrm{Arg}^{101}$. In the hFSHR, Leu ${ }^{55}$ makes hydrophobic contacts with $\operatorname{Arg}^{42}$ of hFSH- $\alpha$, and Leu ${ }^{99}$ and $\mathrm{Tyr}^{103}$ of hFSH- $\beta$. In the sbsFSHR, $\mathrm{Gln}^{70}$ is equivalent to hFSHR Leu ${ }^{55}$, which still allows hydrophobic interactions with $\mathrm{Lys}^{45}$ of $\operatorname{sbsFSH}-\alpha$ and Gly ${ }^{94}$ and $\mathrm{Ser}^{98}$ of sbsFSH- $\beta$ (Mateos et al., 2003). In the second specificity pocket of the hFSHR the side chain of Lys ${ }^{179}$ hydrogen bonds with $\mathrm{Ser}^{89}$ and Asp ${ }^{90}$ of hFSH- $\beta$. In sbsFSH- $\beta$, Thr ${ }^{84}$ corresponds to human $\mathrm{Ser}^{89}$; both hydroxyl side chain amino acids, and human $\mathrm{Asp}^{90}$ is substituted by Glu ${ }^{85}$, both negatively charged. Thus, these sbsFSH residues could host the side chain of sbsFSHR $\operatorname{Arg}^{220}$, a polar hydrophilic positively charged residue equivalent to hFSHR Lys ${ }^{179}$. The sides of this channel are formed by the basic residues Lys ${ }^{54}$ and Lys ${ }^{93}$ of sbsFSH- $\alpha$ (Lys ${ }^{51}$ and Lys ${ }^{91}$ in hFSH- $\alpha$ ), which would make salt bridges with two conserved acidic residues in the sbsFSHR, Asp ${ }^{190}$ 
and $\mathrm{Asp}^{193}$. The third specificity determinant is based on polar interactions of the contiguous residues $\mathrm{Arg}^{97}$ and $\mathrm{Val}^{96}$ of hFSH- $\beta$ with the hFSHR residues Glu ${ }^{76}$ and $\mathrm{Arg}^{101}$ respectively. These two residues are spatially adjacent in the human receptor, however, in the sbsFSHR the additional LRR would originate an extra turn there, spatially separating the equivalent sea bass residues, and therefore preventing the formation of equivalent bonds. Consistently, those human residues are not conserved in sea bass.

For the LHR there is no crystal structure available, but six ionizable amino acids of the rat LHR (rLHR) EC domain involved in ligand binding (Bhowmick et al., 1999) are conserved in the sbsLHR, or substituted by residues with similar size, shape and chemical composition. These are rLHR Glu ${ }^{132}$, Asp ${ }^{135}$, Lys ${ }^{158}$, Lys $^{183}$, Glu ${ }^{184}$ and Asp ${ }^{206}$, which correspond to Asp ${ }^{158}, \mathrm{Asp}^{161}, \mathrm{Asn}^{184}, \mathrm{Lys}^{209}, \mathrm{Asn}^{210}$ and $\mathrm{Asp}^{232}$ in the sbsLHR. Besides, two residues located in the LRR3 of the hLHR, namely Asn ${ }^{104}$ that is an LH-selective determinant (Vischer et al., 2003a), and Ile ${ }^{114}$ that is essential for ligand bind ing (Leung et al., 2006), are conserved in sbsLHR (Asn ${ }^{111}$, Ile ${ }^{118}$ ). On the other hand, the rat and human LHRs have in their LRRs two cysteines important for hormone binding (Cys ${ }^{109}$ and Cys ${ }^{134}$ in the rLHR), which are probably bonded (Zhang et al., 1996). But, sbsLHR, and all known fish LHRs, contain a serine ( $\operatorname{sbsLHR}$ Ser ${ }^{133}$ ) instead of rLHR Cys ${ }^{109}$, what prevents disulfide bonding. Even so, the sbsLHR, like other fish LHRs, can be activated by mammalian LH, indicating that its presence is not essential for fish LHR functionality.

Following the LRRs is the C-terminal cysteine-rich domain, which has six conserved cysteines in all known FSHRs and LHRs, including the ones of sea bass. A crucial ligand binding site has been found in hFSHR between the third and fourth cysteine of this domain (Kene et al., 2005), but, interestingly, this site do es not exist in fish FSHRs, due to a 30 amino acid deletion (Fig. 2). Unfortunately, direct evidence of specific contacts is not available, as the crystal structure of the hFSH-FSHR ${ }_{1-250}$ complex does not contain this domain. 
Despite the distinct features found in the EC regions of fish and mammalian FSHRs, fish receptors respond to mammalian FSH, suggesting that those differences can be important but not fundamental for ligand binding. Besides, this is consistent with the existence of multiple FSH selective determinants in the hFSHR (Vischer et al., 2006).

sbsFSHR expression was exclusively detected in gonads, as found in other fish species (Oba et al., 1999b; Bogerd et al., 2001). On the contrary, the $s b s L H R$ is mainly expressed in gonads, but also in other sea bass tissues, which is in line with reports in mammals (Frazier et al., 1990; Meduri et al., 1997; Rao, 2001) and different fish species (Oba et al., 1999a; Kumar et al., 2001b; Vischer and Bogerd, 2003; Kwok et al., 2005). In the sea bass, extragonadal expression of $L H R$ was remarkable in head kidney. Similarly, $L H R$ expression in African catfish was found to be higher in head kidney than in gonads (Vischer and Bogerd, 2003). Moreover, in coho salmon two gonadotropin preparations effectiv ely stimulated cortisol and androstenedione secretion by the interrenal tissue, which it is located in the head kidney (Schreck et al., 1989). Despite many reports on the presence of LHR in diverse extragonadal tissues, their significance remains poorly understood due to the absence of in vivo data on their functionality (Pakarainen et al., 2005).

In situ hybridization showed a strong expression of the $s b s F S H R$ in previtelogenic and early vitelogenic oocytes, as observed in Nile tilapia (Oba et al., 2001) and zebrafish ovaries (Kwok et al., 2005). This follicle-stage dependent expression strongly suggests a role for the sbsFSHR in oocyte growth. However, in adult sea bass (Mateos et al., 2003) and other fish species (Yoshiura et al., 1997; Kajimura et al., 2001; So et al., 2005), maximum levels of FSH- $\beta$ expression are detected at the final stages of gamete maturation. This mismatch between the expression of FSH- $\beta$ and $s b s F S H R$ could be explained by the spawning strategy of sea bass. The sea bass has a group-synchronous ovarian development and spawns several times per reproductive season. Steady high levels of FSH would ensure follicle growth of 
different clutches of oocytes during a rather long period, but only those ones producing FSHR would be responsive.

In mammals, glycoprotein hormone/receptor interactions are very specific. Conversely, functional studies in salmonids, catfish and cyprinids question the binding specificity between teleost gonadotropins and their respective receptors (Yan et al., 1992, Miwa et al., 1994; Oba et al., 1999a,b; Bogerd et al., 2001; Vischer et al., 2003b; Kumar et al., 2001a,b; Basu and Bhattacharya, 2002; Kwok et al., 2005). In this study, sbsFSHR displayed ligand selectivity as it was only activated by bFSH, but not by bLH. Besides, the same results were obtained with conditioned medium of $\mathrm{CHO}-\mathrm{K} 1$ stable clones producing recombinant sea bass $\mathrm{FSH}$ and $\mathrm{LH}$; only recombinant sbsFSH could stimulate cAMP production (unpublished data). On the contrary, the sbsLHR was activated by both bLH and bFSH. The same behaviour was observed in zebrafish and amago salmon, bLH and bFSH could activate their LHRs, while the FSHRs were only responsive to bFSH (Kwok et al., 2005, Oba et al., 1999a,b). Nevertheless, other mammalian hormones can act in a different way in other fish receptors (Kumar et al., 2001a,b; Bogerd et al., 2001; Vischer and Bogerd, 2003). This complex cross-activation warns about the use of mammalian hormones in aquaculture, where they have been applied pharmacologically to overcome reproductive dysfunctions caused by confinement.

Despite the promiscuous activation of the sbsLHR by bovine gonadotropins, this receptor was only activated by recombinant sbsLH, but not sbsFSH. This divergent response of the sbsLHR to bFSH and sbsFSH is probably due to sequence differences in their $\beta$ subunits. In the mammalian LH $\beta$-subunits, the presence of a net positive charge in the stretch between conserved Cys ${ }^{10-11}$ (small seat-belt loop) is important for LHR binding. However, bFSH, sbsFSH and sbsLH, like other mammalian FSHs, have a clear negative net charge in this area; thus, charge differences are not related to the promiscuous activation of 
the sbsLHR. Indeed, fish $\beta$-subunits also contain a specificity determinant in th is loop, but it is not related to charge differences (Vischer et al., 2004). Considering the whole sequence of the bovine and sea bass $\beta$-subunits, bFSH is more similar to sbsLH than to sbsFSH, particularly between $\mathrm{Cys}^{1-2}$ and $\mathrm{Cys}^{6-7}$. Furthermore, sbsF SH has five amino acids less than the other three gonadotropins between $\mathrm{Cys}^{6-8}$, resulting in a shorter $\beta 3$ loop. This fact could influence hormone binding, as it has been suggested that the tips of $\beta 1$ and $\beta 3$ loops in the hCG contact the receptor (Moyle et al., 2004). Another different feature of the sbsFSH is the spatial position of the C-terminal seat-belt loop, between $\mathrm{Cys}^{11-12}$. In the bovine subunits and sbsLH- $\beta$ these residues are near $\beta 1$ and $\beta 3$ loops, due to a disulfide bond between Cys ${ }^{12}$ and $\mathrm{Cys}^{3}$. Nevertheless, in sbsFSH, as in other perciform and salmonid species, $\mathrm{Cys}^{3}$ is missing (Mateos et al., 2003; Swanson et al., 2003). Instead, a cysteine is found in the very Nterminus, which bonds with $\mathrm{Cys}^{12}$, placing the tail of the seat-belt far from $\beta 1$ and $\beta 3$ loops. This difference could denote a different binding mode for the gonadotropin receptors of sea bass and other fish species.

In summary, we have characterized, for the first time, both gonadotropin receptors in a Perciform species. sbsLHR sequence is more conserved than sbsFSHR when compared to other fish and mammalian receptors; particularly in the EC domain, where the sbsFSHR contains an additional LRR. While $s b s F S H R$ is exclusively expressed in gonads, $s b s L H R$ shows a lower and more ubiquitous expression. Finally, the sbsLHR was activated by both bovine gonadotropins, but our results suggest that the interactions between the sea bass gonadotropins and their receptors are specific. However, additional experiments with different hormone doses are needed to further assess this specificity. 


\section{Acknowledgements}

We acknowledge Prof. Adelino Canario from the University of Algarve, Portugal for providing us the sea bass cDNA testicular library and the NIDDK's National Hormone \& Peptide Program and A.F. Parlow for providing bovine FSH and LH.

This work was financially supported by a Spanish Ministry of Science and Technology grant (AGL 2001-1257) and a Generalitat Valenciana grant (Grupos 04/80) to MC. The European Social Fund and Portuguese National funds under Portuguese National Science Foundation (FCT) POCI-2010 SFRH/BD/6901/2001 covered a fellowship received by AR.

\section{References}

Allan, C.M., Handelsman, D.J., 2005. In vivo FSH actions. In: Skinner, M.K. and Griswold, M.D. (eds.), Sertoli Cell Biology. Elsevier Academic Press, San Diego, CA, USA, pp. 171-197.

Alvarino, J.M.R., Carrillo, M., Zanuy, S., Prat, F., Mañanós, E., 1992. Pattern of sea bass oocyte development after ovarian stimulation by LHRHa. J. Fish Biol. 41, 965-970.

Ascoli, M., Fanelli, F., Segaloff, D.L., 2002. The Lutropin/Choriogonadotrop in receptor, a 2002 perspective. Endocr. Rev. 23, 141-174.

Basu, D., Bhattacharya, S., 2002. Pur ification of two types of gonadotropin receptors from carp ovarian follicles: overlapping recognition by two different ligands. Gen. Comp. Endocrinol. 129, 152-162.

Bhowmick, N., Narayan, P., Puett, D., 1999. Identification of Ionizable Amino Acid Residues on the Extracellular Domain of the Lutropin Receptor Involved in Ligand Binding. Endocrinology 140, 4558-4563.

Bogerd, J., Blomenrohr, M., Andersson, E., van der Putten, H.H.A.G., Tensen, C.P., Vischer, H.F., Granneman, J.C.M., Janssen-Dommerholt, C., Goos, H.J.T., Schulz, R.W., 2001. Discrepancy between molecular structure and ligand selectivity of a testicular folliclestimulating hormone receptor of the African Catfish (Clarias gariepinus). Biol. Reprod. 64, 1633-1643.

Bousfield, G.R., Perry, W.M., Ward, D.N., 1994. Gon adotropins: chemistry and biosyn thesis. In: Knobil, E., Neill, J.D. (eds.), The Physiology of Reproduction, Raven Press, New York, pp. 1749-1792. 
Braun, T., Schofield, P.R., Sprengel, R., 1991. Amino-terminal leucine-rich repeats in gonadotropin receptors determine hormone selectivity. EMBO J. 10, 1885-1890.

Cerdá-Reverter, J.M., Ling, M.K., Schioth, H.B., Peter, R.E., 2003. Molecular cloning, characterization and brain mapping of the melanocortin 5 receptor in the goldfish. $\mathrm{J}$. Neurochem. 87, 1354-1367.

Chappel, S.C., Howles, C., 1991. Reevaluation of the roles of luteinizing hormone and follicle- stimulating hormone in the ovulatory process. Hum. Reprod. 6, 1206-1212.

Chen, C., Okayama, H., 1987. High-efficiency transformation of mammalian cells by plasmid DNA. Mol. Cell. Biol. 7, 2745-2752.

Davis, D., Liu, X., Segaloff, D.L., 1995. Identification of the sites of N-linked glycosylation on the follicle-stimu lating hormone (FSH) receptor and assessment of their role in FSH receptor function. Mol. Endocrinol. 9, 159-170.

Dias, J.A., Cohen, B.D., Lindau-Shepard, B., Nechamen, C.A., Peterson, A.J., Schmidt, A., 2002. Molecular, structural, and cellular biology of follitropin and follitropin receptor (Vitamins and Hormones, vol 64), pp. 249-322, Academic Press.

Fan, Q.R., Hendrickson, W.A., 2005. Structure of human follicle-stimulating hormone in complex with its receptor. Nature 433, 269-277.

Frazier, A.L., Robbins, L.S., Stork, P.J., Sprengel, R., Segaloff, D.L., Cone, R.D., 1990. Isolation of TSHand $\mathrm{LH} / \mathrm{CG}$ receptor cDNAs from human thyroid: regulation by tissue specific splicing. Mol. Endocrinol. 4, 1264-1276.

Gudermann, T., Nurnberg, B., Schultz, G., 1995. Receptors and G proteins as primary components of transmembrane signal transduction. Part 1. G-protein-coupled receptors: structure and function. J. Mol. Med. 73, 51-63.

Herlaut, M., 1960. Étude critique de deux techniques nouvelles destine à metre en evidence les différents categories cellulaires presén te dans le glande pituitaire. Bulletin de Microscopies Appliquée. 10, 37-44.

Hsu, S.Y., Kudo, M., Chen, T., Nakabayashi, K., Bhalla, A., van der Spek, P.J., van Du in, M., Hsueh, A.J.W., 2000. The Three Subfamilies of Leucine-Rich Repeat-Containing G Protein-Coupled Receptors (LGR): Identification of LGR6 and LGR7 and the Signaling Mechanism for LGR7. Mol. Endocrinol. 14, 1257-1271.

Kajimura, S., Yoshiura, Y., Suzuki, M., Aida, K., 2001. cDNA cloning of two gonadotropin beta subunits (GTH-Ibeta and -IIbeta) and their expression profiles during gametogenesis in the Japanese flounder (Paralichthys olivaceus). Gen. Comp. Endo crinol. 122, 117-129.

Kene, P.S., Dighe, R.R., Mahale, S.D., 2005. Delineation of regions in the extracellular domain of follicle-stimulating hormone receptor involved in hormone binding and signal transduction. Am. J. Reprod. Immunol. 54, 38-48.

Kobe, B. and Kajava, A.V., 2001. The leucine-rich repeat as a protein recognition motif. Curr. Opin. Struct. Biol. 11, 725-732. 
Kumar, R.S., Shigeho, I., Trant, J.M., 2001a. Molecular Biology of Channel Catfish Gonadotropin Receptors: 1. Cloning of a Functional Luteinizing Hormone Receptor and Preovulatory Induction of Gene Expression. Biol. Reprod. 64, 1010-1018.

Kumar, R.S., Ijiri, S., Trant, J.M., 2001b. Molecular Biology of the Channel Catfish Gonadotropin Receptors: 2. Complementary DNA Cloning, Functional Expression, and Seasonal Gene Expression of the Follicle-Stimulating Hormone Receptor. Biol. Reprod. 65, 710-717.

Kumar, S., Tamura, K., Jakobsen, I.B., Nei, M., 2001. MEGA2: molecular evolutionary genetics analys is software. Bioinformatics 17, 1244-1245.

Kwok, H.F., So, W.K., Wang, Y., Ge, W., 2005. Zebrafish Gonadotropins and Their Receptors: I. Cloning and Characterization of Zebrafish Follicle-Stimulating Hormone and Luteinizing Hormone Receptors-- Evidence for Their Distinct Functions in Follicle Development. Biol. Reprod. 72, 1370-1381.

Leung, M.Y.-K., Steinbach, P.J., Bear, D., Baxendale, V., Fechner, P.Y., Rennert, O.M., Chan, W.Y., 2006. Biological Effect of a Novel Mutation In The Third Leucine-Rich Repeat of Human Luteinizing Hormone Receptor. Mol. Endocrinol. 20, 2493-2503.

Martinez, G., Shaw, E.M., Carrillo, M., Zanuy, S., 1998. Protein salting-out method applied to genomic DNA isolation from fish whole blood. Biotechniques 24, 238-239.

Mateos, J., Mañanos, E., Martinez-Rodriguez, G., Carrillo, M., Querat, B., Zanuy, S., 2003. Molecular characterization of sea bass gonadotropin subunits (alpha, FSHbeta, and LHbeta) and their expression during the reproductive cycle. Gen. Comp. Endocrinol. 133, 216-232.

Mayer, I., Shackley, S.E., Witthames, P.R., 1990. Aspects of the reproductive biology of the bass, Dicentrarchus labrax L. II. Fecundity and pattern of oocyte development. J. Fish Biol. 36, 141-148.

Means, A.R., Dedman, J.R., Tash, J.S., Tindall, D.J., van Sickle, M., Welsh, M.J., 1980. Regulation of the testis sertoli cell by follicle stimulating hormone. Annu. Rev. Physiol. $42,59-70$.

Meduri, G., Charnaux, N., Loo sfelt, H., Jolivet, A., Spyratos, F., Brailly, S., Milgrom, E., 1997. Luteinizing hormone/human chorionic gonadotrop in receptors in breast cancer. Cancer Res. 57, 857-864.

Miwa, S., Yan, L., Swanson, P., 1994. Localization of two gonadotropin receptors in the salmon gonad by in vitro ligand autoradiography. Biol. Reprod. 50, 629-642.

Moyle, W.R., Xing, Y., Lin, W., Cao, D., Myers, R.V., Kerrigan, J.E., Bernard, M.P., 2004 Model of glycoprotein hormone receptor ligand binding and signaling. J. Biol. Chem. $279,44442-44459$.

Nelson, J.S.,1994. Fishes of the World, Wiley, New York. 
Oba, Y., Hirai, T., Yoshiura, Y., Kobayashi, T., Nagahama, Y., 2001. Fish gonadotropin and thyrotropin receptors: the evolution of glycoprotein hormone receptors in vertebrates. Comp. Biochem. Physiol. B Biochem. Mol. Biol. 129, 441-448.

Oba, Y., Hirai, T., Yoshiura, Y., Yoshikuni, M., Kawauchi, H., Nagahama, Y., 1999a. Cloning, Functional Characterization, and Expression of a Gonadotropin Receptor cDNA in the Ovary and Testis of Amago Salmon (On corhynchus rhodurus). Biochem. Biophys. Res. Commun. 263, 584-590.

Oba, Y., Hirai, T., Yoshiura, Y., Yoshikuni, M., Kawauchi, H., Nagahama, Y., 1999b. The Duality of Fish Gonado tropin Receptors: Cloning and Functional Characterization of a Second Gonadotropin Receptor cDNA Expressed in the Ovary and Testis of Amago Salmon (Oncorhynchus rhodurus). Biochem. Biophys. Res. Commun. 265, 366-371.

Pakarainen, T., Zhang, F.P., Poutanen, M., Huhtaniemi, I., 2005. Fertility in luteinizing hormone receptor-knockout mice after wild-type ovary transplantation demonstrates redundancy of extragonadal luteinizing hormone action. J. Clin. Invest. 115, 1862-1868.

Pierce, J.G. and Parsons, T.F., 1981. Glycoprotein Hormones: Structure and Function. Annu. Rev. Biochem. 50, 465-495.

Rao, C.V., 2001. An overview of the past, present, and future of nongonadal LH/hCG action s in reproductive biology and medicine. Semin. Reprod. Med. 19, 7-17.

Richards, J.S., 1994. Hormonal control of gene expression in the ovary. Endocr. Rev. 15, 725751.

Sambrook, J., Russell, D.W., 2001. Molecular Cloning: A Laboratory Manual, Cold Spring Harbor Laboratory Press, New York.

Schreck, C.B., Bradford, C.S., Fitzpatrick, M.S., Patiño, R., 1989. Regulation of the interrenal of fishes: non-classical control mechanisms. Fish Physiol. Biochem. 7, 259-265.

Simoni, M., Gromoll, J., Nieschlag, E., 1997. The Follicle-Stimulating Hormone Receptor: Biochemistry, Molecular Biology, Physiology, and Pathophysiology. Endocr. Rev. 18, 739-773.

Smits, G., Campillo, M., Govaerts, C., Janssens, V., Richter, C., Vassart, G., Pardo, L., Costagliola, S., 2003. Glycoprotein hormone receptors: determinants in leucine-rich repeats responsible for ligand specificity. EMBO J. 22, 2692-2703.

So, W.K., Kwok, H.F., Ge, W., 2005. Zebrafish gonadotropins and their receptors: II. Cloning and characterization of zebrafish follicle-stimulating hormone and luteinizing hormone subunits--their spatial-temporal expression patterns and receptor specificity. Biol. Reprod. 72, 1382-96.

Swanson, P., Dickey, J.T., Campbell, B., 2003. Biochemistry and physiology of fish gonadotropins. Fish Physiol Biochem. 28, 53-59. 
Szkudlinski, M.W., Fremont, V., Ronin, C., Weintraub, B.D., 2002. Thyroid-Stimulating Hormone and Thyroid-Stimulating Hormone Receptor Structure-Function Relationships. Physiol. Rev. 82, 473-502.

Tao, Y.X., Abell, A.N., Liu, X., Nakamura, K., Segaloff, D.L., 2000. Constitutive Activation of G Protein-Coupled Receptors as a Result of Selective Substitution of a Conserved Leucine Residue in Transmembrane Helix III. Mol. Endocrinol. 14, 1272-1282.

Themmen, A.P.N. and Huhtaniemi, I.T., 2000. Mutations of gonadotropins and gonadotropin receptors: elucidating the physiology and pathophysiology of pituitary-gonadal function. Endocr. Rev. 21, 551-583.

Thompson, J.D., Gib son, T.J., Plewniak, F., Jeanmougin, F., Higgins, D.G., 1997. The CLUSTAL X windows interface: flexible strategies for multiple sequence alignment aided by quality analysis tools. Nucleic Acids Res. 25, 4876-4882.

Vassart, G., Pardo, L., Costagliola, S., 2004. A molecular dissection of the glycoprotein hormone receptors. Trends Biochem. Sci. 29, 119-126.

Vischer, H.F., Bogerd, J., 2003. Cloning and Functional Characterization of a Gonadal Luteinizing Hormone Receptor Complementary DNA from the African Catfish (Clarias gariepinus). Biol. Reprod. 68, 262-271.

Vischer, H.F., Granneman, J.C.M., Bogerd, J., 2003a. Opposite Contribution of Two LigandSelective Determinants in the N-Terminal Hormone-Binding Exodomain of Human Gonadotropin Receptors. Mol Endocrinol 17, 1972-1981.

Vischer, H.F., Granneman, J.C., Linskens, M.H., Schulz, R.W., Bogerd, J., 2003b. Both recombinant African catfish $\mathrm{LH}$ and FSH are able to activate the African catfish FSH recep tor. J. Mol. Endocrinol. 31, 133-140.

Vischer, H.F., Marques, R.B., Granneman, J.C.M., Linskens, M.H.K., Schulz, R.W., Bogerd, J., 2004. Receptor-selective determinants in catfish gonadotropin seat-belt loops. Mol. Cell. Endocrinol. 224, 55-63.

Vischer, H.F., Granneman, J.C.M., Bogerd, J., 2006. Identification of FSH-selective \{beta\}strands in the N-terminal hormone-binding exodomain of human gonadotrop in receptors. Mol. Endocrinol. 20, 1880-1893.

Vu-Hai, M.T., Huet, J.C., Echasserieau, K., Bidart, J.M., Floiras, C., Pernollet, J.C., Milgrom, E., 2000. Posttranslational modifications of the lutrop in receptor: mass spectrometric analysis. Biochemistry 39, 5509-5517.

Wellbrock, C., Geissinger, E., Gomez, A., Fischer, P., Friedrich, K., Schartl, M., 1998. Signalling by the on cogenic receptor tyrosine kinase Xmrk leads to activation of STAT5 in Xiphophorus melanoma. Oncogene 16, 3047-3056.

Wong, T.T., Gothilf, Y., Zmora, N., Kight, K.E., Meiri, I., Elizur, A., Zohar, Y., 2004. Developmental Express ion of Three Forms of Gonadotropin-Releasing Hormone and Ontogeny of the Hypothalamic-Pituitary-Gonadal Axis in Gilthead Seabream (Sparus aurata). Biol. Reprod. 71, 1026-1035. 
Yan, L., Swanson, P., Dickhoff, W.W., 1992. A two-receptor model for salmon gonadotropins (GTH I and GTH II). Biol. Reprod. 47, 418-427.

Yoshiura, Y., Kobayashi, M., Kato, Y., Aida, K., 1997. Molecular cloning of the cDNAs encoding two gonadotropin beta subunits (GTH-I beta and -II beta) from the goldfish, Carassius auratus. Gen. Comp. Endocrinol. 105, 379-389.

Zhang, R., Buczko, E., Dufau, M.L., 1996. Requirement of Cysteine Residues in Exons 1-6 of the Extracellular Domain of the Luteinizing Hormone Receptor for Gonadotropin Bind ing. J. Biol. Chem. 271, 5755-5760. 


\section{Figure Legends}

Figure 1 Nucleotide and deduced amino acid sequence of the $s b s F S H R$ cDNA. Numbers on the left refer to position of the amino acid (top) and the nucleotide residues (bottom). Amino acid numbering begins with the proposed initial methionine. The predicted signal peptide is indicated in bold italics. Cysteine residues of the $\mathrm{N}$ - and $\mathrm{C}$-terminal cysteine-rich regions of the extracellular domain are indicated by grey boxes. The ten $\beta$-strand motifs (X-L-X-L-X) of the LRRs, identified by Pfam Blast and sequence alignment with the hFSHR, are shown as arrows. Two potential N-linked glycosylation sites, conserved in the hFSHR, are indicated by open boxes. The position of the seven predicted transmembrane helixes is shown as black boxes. The nucleotide sequence has been submitted to the Gen Bank and is available under the accession number $\underline{\mathbf{A Y 6 4 2 1 1 3}}$.

Figure 2 Amino acid sequence alignment of the extracellular domain and the region that links with the transmembrane domain of the FSHRs. Accession numbers: human (Hum) AY429104, sea bass (Sbs) $\underline{\mathbf{A Y 6 4 2 1 1 3}}$, Nile tilapia (Til) AB041762, seabream (Sb) AY587262, amago salmon (As) AB030012, Atlantic salmon (Ats) AJ567667, rainbow trout (Rtr) AF439405, zebrafish (Zbf) AY278107 African catfish (Ac) AJ012647, channel catfish (Cc) AF285182. The numbers on the right refer to amino acid position. sbsFSHR (Sbs) sequence is highlighted in bold letters. Amino acid residues conserved in all sequences are boxed in grey. Asterisks indicate the cysteines conserved in the sbsFSHR. Black bars over the sequence indicate the $\beta$-strand motif (X-L-X-L-X) of the LRRs.

Figure 3 Nucleotide and deduced amino acid sequence of the $s b s L H R$ cDNA. Numbers on the left refer to position of the amino acid (top) and the nucleotide residues (bottom). Amino acid numbering begins with the proposed initial methionine. The predicted signal peptide is 
indicated in bold italics. Cysteines of the $\mathrm{N}$ - and $\mathrm{C}$-terminal cysteine-rich regions of the extracellular domain are indicated by grey boxes. Two conserved adjacent cysteines, present in the intracellular domain and predicted to be palmitoylated are also indicated by grey boxes. The nine $\beta$-strand motifs (consensus sequence: X-L-X-L-X) of the LRRs, found by Pfam Blast and sequence alignments, are shown as arrows. Two potential N-linked glycosylation sites, conserved in the hLHR, are indicated by open boxes. The position of the seven predicted transmembrane domains is shown as black boxes. The nucleotide sequence has been submitted to the Gen Bank and is available under the accession number $\underline{\mathbf{A Y 6 4 2 1 1 4}}$.

Figure 4 Phylogenetic tree of fish GpHR amino acid sequences inferred from the NeighborJoining method. Accession numbers: sbsLHR (国642114), amago salmon LHR (AB030005), channel catfish LHR (AF285181), Nile tilapia LHR (AB041763), gilthead seabream LHR (AY587261), African catfish LHR (AF324540), rainbow trout LHR (AF439404), Atlantic salmon LHR (AJ579790), zebrafish LHR (AY424302), amago salmon TSHRa (AB030954), amago salmon TSHRb (AB030955), striped sea bass TSHR (AF239761), Nile tilapia TSHR (AB047390), Atlantic salmon TSHR (AF406603), African catfish TSHR (AY129556), sbsFSHR (AY642113), African catfish FSHR (AJ012647), channel catfish FSHR (AF285182), amago salmon FSHR (AB030012), Atlantic salmon FSHR (AJ567667), rainbow trout FSHR (AF439405), Nile tilapia FSHR (AB041762), gilthead seabream FSHR (AY587262), zebrafish FSHR (AY278107). The LGR sequence from the Caenorhabditis elegans (AF224743) was used as the outgroup. Bootstrap values (in \%) from 1000 replicates are indicated for each tree node.

Figure 5 RT-PCR expression analysis of $s b s F S H R(\mathbf{A})$ and $s b s L H R(\mathbf{B})$ in adult fish tissues. Specific primers encoding a segment of the transmembrane or extracellular domain were used 
for cDNA amplification of $s b s F S H R$ and $s b s L H R$ respectiv ely. The presence of introns in these areas of the genes guarantees that amplification comes exclusively from the mRNA. The integrity of the RNAs was verified by uniform amplification of the sea bass $18 S \operatorname{RRNA}$ transcript. (C) Northern blot analysis. Poly (A)+ RNA from ovary (lane 1) and total RNA from testis (lanes 2 and 3) and ovary (lane 4) from 2 adult animals were probed with the full length $s b s F S H R$ cDNA (left panel). Poly (A)+ RNA from ovary was probed with the complete $s b s L H R$ cDNA (right panel), the RNA in this membrane is identical to lane 1 in the left panel. This blot was much longer exposed than the $s b S F H R$ blot. The numbers on the left correspond to the localization of size marker RNAs (in Kb). Arrows indicate the position of two $s b s F S H R$ mRNAs of about 1.8 and $3 \mathrm{~Kb}$, and one $s b s L H R$ transcript of about $3 \mathrm{~Kb}$.

Figure 6 In situ hybridization of $s b s F S H R$ antisense riboprobe in ovary sections of sexually mature females. Expression of $s b S F S H R$ (dark grains) was observed on the follicular wall of oocytes in previtelogenesis (A), in cortical alveoli stage (B) and in later stages of vitelogenesis (C, D). Higher magnification in photomicrograph $\mathbf{D}$ clearly shows expression in the follicular wall (fw) while the surrounding areas are free of signal (zp, zona pellucida; cyv, cortical alveoli; $\mathbf{y v}$, yolk vesicle; $\mathbf{0 o}$, ooplasma). Scale bar: $50 \mu \mathrm{m}$.

Figure 7 Functional analys is of sbsFSHR expressed in HEK293 cells. A stable clone containing the sbsFSHR was transiently transfected with the reporter plasmid pCRE-Luc. (A) Temporal luciferase activity in response to $1 \mu \mathrm{g} / \mathrm{ml}$ of bFSH, bLH or untreated (Control). (B) Luciferase activity after 6-h treatment with different dosis of bFSH and bLH.

Figure 8 Functional analys is of sbsLHR expressed in HEK293 cells. A double stable clone expressing the $s b s L H R$ and the reporter construct pCRE-Luc was developed. (A) Luciferase 
activity after 5-h treatment with different doses of bFSH and bLH. (B) Luciferase activity after 5-h treatment with a single concentration of conditioned medium of cultured $\mathrm{CHO}-\mathrm{K} 1$ wild type cells (Control) or stable clones producing recombinant sea bas s LH or FSH. 
Table 1. Primers used in the PCR experiments ${ }^{\mathrm{a}}$.

\begin{tabular}{|c|c|c|c|c|}
\hline Primer & $\begin{array}{l}\text { Nucleotide } \\
\text { position }\end{array}$ & Sequence $\left(5^{\prime} \rightarrow 3^{\prime}\right)^{b}$ & $\begin{array}{c}\text { Touchdown } \\
\text { Annealing Temp }\end{array}$ & ce \\
\hline fshr 1 & 1419 & TTCCTKATGTGCMACCTIKCMTTTGC & $70^{\circ} \mathrm{C} \max \rightarrow 55^{\circ} \mathrm{C} \min$ & Forward \\
\hline fshr 2 & 2113 & AGGAARGGRTTGGCRCAIGARTTKAT & $70^{\circ} \mathrm{C} \max \rightarrow 55^{\circ} \mathrm{C} \min$ & Reverse \\
\hline fshr 6 & 1779 & RYSAGYATCTGYCTICCCATGGATGT & $65^{\circ} \mathrm{C} \max \rightarrow 55^{\circ} \mathrm{C} \min$ & Forward \\
\hline fshr 8 & 699 & CTGACTATYTCMAACACNGGNCT & $65^{\circ} \mathrm{C} \max \rightarrow 50^{\circ} \mathrm{C} \min$ & Forward \\
\hline fshr 9 & 1865 & GAAAGCCAGGATGTTGAGGAG & $65^{\circ} \mathrm{C} \max \rightarrow 50^{\circ} \mathrm{C} \min$ & Reverse \\
\hline fshr 25 & 1339 & TCCTCATCTGGATCATCTCCAT & $65^{\circ} \mathrm{C} \max \rightarrow 55^{\circ} \mathrm{C} \min$ & Forward \\
\hline fshr 26 & 1621 & GTTAATGTGAACACTGACAGCTCA & $65^{\circ} \mathrm{C} \max \rightarrow 55^{\circ} \mathrm{C} \min$ & Reverse \\
\hline Ihr 21 & 1090 & СТСТСАTCACAATAAGTAGAGTCA & $60^{\circ} \mathrm{C} \max \rightarrow 55^{\circ} \mathrm{C}$ min & Reverse \\
\hline Ihr 23 & 811 & TGGATCACTCTGAGGTTTCGATTATTC & $70^{\circ} \mathrm{C} \max \rightarrow 55^{\circ} \mathrm{C} \min$ & Reverse \\
\hline Ihr 24 & 535 & AGGTTATTGAATGTCCTTCTGCCAATGTG & $60^{\circ} \mathrm{C} \max \rightarrow 55^{\circ} \mathrm{C} \min$ & Reverse \\
\hline Ihr 30 & 1 & CACTTGATGAGAAGTTGAGTAACA & $60^{\circ} \mathrm{C} \max \rightarrow 55^{\circ} \mathrm{C} \min$ & Forward \\
\hline Ihr 35 & 484 & TCCAGAACACGAGGAGTCTGAT & $70^{\circ} \mathrm{C} \max \rightarrow 55^{\circ} \mathrm{C} \min$ & Forward \\
\hline 5'18S & & TCAAGAACGAAAGTCGGAGG & $65^{\circ} \mathrm{C}$ & Forward \\
\hline $3 ' 18 S$ & & GGACATCTAAGGGCATCACA & $65^{\circ} \mathrm{C}$ & Reverse \\
\hline
\end{tabular}

a Primers were obtained from Invitrogen Corp.(Carlsbad, CA).

${ }^{\mathrm{b}} \mathrm{Y}=\mathrm{C}$ or $\mathrm{T}, \mathrm{R}=\mathrm{G}$ or $\mathrm{A}, \mathrm{K}=\mathrm{T}$ or $\mathrm{G}, \mathrm{M}=\mathrm{A}$ or $\mathrm{C}$, and $\mathrm{I}=$ deoxyinosine.

${ }^{c}$ Touchdown-PCR was used for amplification. Maximum and minimum temperatures achieved during annealing step, are indicated for each primer. 
1 CACACTTCT TCCCTCTTCAACCTGGCGGT GAACCCAGAGTTGTGAGACGAAAAAAAAAAACAACCCATTCATGA TATCAAATGTGGAGTGTGGGCTCTGT 101 GAGAAGGCCTGAACACACGTGAACACA GA GGGAAACAACAGT GA GAGAG TGT GA GGA GAAGCAGAAGAA GAAGAAGAGAAACAACC TGGAC TGT GGACAG $\begin{array}{lllllllllllllllllllllllllllllllllll}1 & & & \boldsymbol{M} & \boldsymbol{M} & \boldsymbol{M} & \boldsymbol{V} & \boldsymbol{M} & \boldsymbol{I} & \boldsymbol{L} & \boldsymbol{I} & \boldsymbol{M} & \boldsymbol{L} & \boldsymbol{M} & \boldsymbol{I} & \boldsymbol{L} & \boldsymbol{M} & \boldsymbol{I} & \boldsymbol{K} & \boldsymbol{T} & \boldsymbol{A} & \boldsymbol{T} & \boldsymbol{A} & \mathrm{S} & \mathrm{V} & \mathrm{P} & \mathrm{G} & \mathrm{P} & \mathrm{E} & \mathrm{M} & \mathrm{D} & \mathrm{V} & \mathrm{K} & \mathrm{P}\end{array}$ 201 ACTGCGA TGATGATGGT GA TGA TTCTCATAATGT TGA TGATTCT GAT GA TAAAGACGGCAACAGCC TCG GT GCC TGGCCCAGAGAT GGACG TTAAACCAG

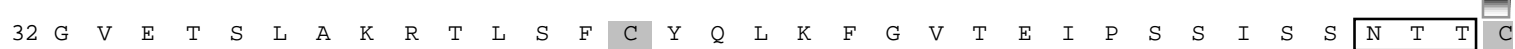
301 GAGTGGA GACCAGC TTGGCCAAACGAACCCTGAGCTTCTGCTACCAGTTGAAGT TTGGGGTCACAGAGA TTCCC TCCAGCATCT CCAGCAACACCACATG

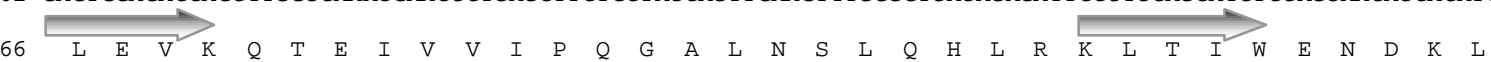
401 CCTGGAAGT TAAGCAGACGGAGATCGTAG TGATTCCCCAGGGCGCCCTCAACAGCCTGCAGCACCTCAGGAAAC TCACCATATGGGAGAACGACAAGCTG

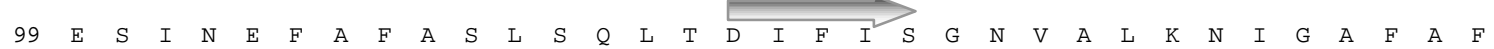
501 GAGAGTA TCAATGAGTT TGCCT TCGCCAGCCTCTCTCAGCTCACCGATATCT TCATCTCTGGGAATGTTGCGTTAAAAAATATAGGAGCTT TTGCTTTCT

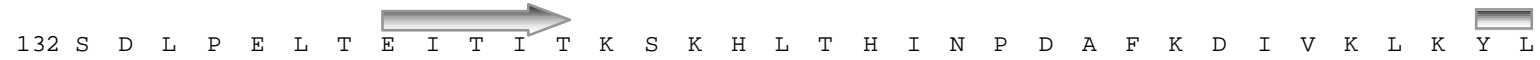
601 CTGATCT GCCTGAACTCACTGAGA TAACCATAACAAAGT CAAAACACCTGACACACA TCAATCCAGATGCATTCAAGGACATTG TGAAACT GAAGTATCT

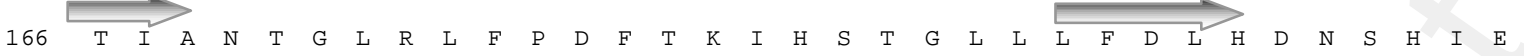
701 GACCATCGCCAACACTGGACTGAGGCT TT TTCCAGAC TTCACCAAGA TCCACTCCACAGGCCTGCT TCT GT TTGACCTGCACGACAACAGCCACATAGAG

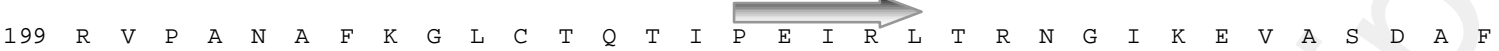
801 AGAGTCCCCGCCAATGCTTTCAAAGGCCTCTGCACTCAAACTATCCCTGAGA TACGGCTCACCAGAAAT GGCATCAAGGAGGTGGCAAGTGACGCCTTCA

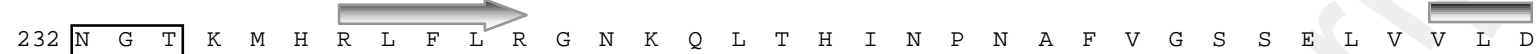
901 ACGGCACAAAGA TGCACAGATT GT TCCTAAGA GGCAACAAACAGCTTACTCACA TCAAT CCCAACGCCT TTGTGGG TTCCAGTGAG TTGGTGGTACTGGA

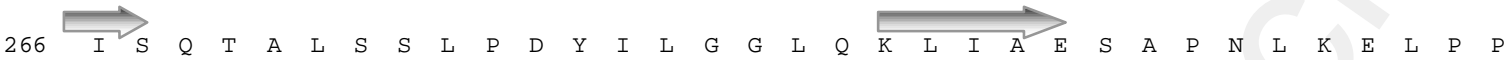
1001 CATT TCCCAGACAGCCCTCAGC TCCCT GCCGGACTACATCCTCGGTGGACTCCAGAAGC TGATCGCAGAGT CCGCCCCCAATCT GAAGGAGCTTCCTCCT

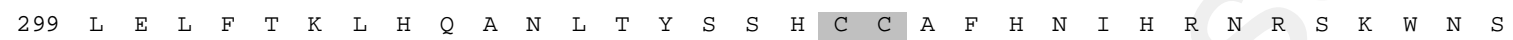
1101 CTGGAGCTC TTCACCAAAC TGCACCAGGCCAACC TGACG TAC TCGTCACACT GC TGCGCCTTCCATAACATACACAGGAACAGA TCAAA GT GGAACTCCC

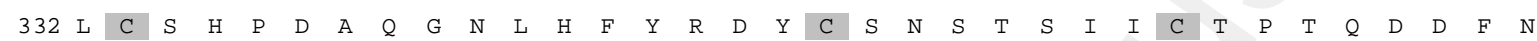
1201 TGTGCTCCCACCCCGATGCTCAGGGCAACCTTCACTTCTACAGGGACTACTGCTCCAACTCCACCTCCATCATCTGCACCCCAACCCAAGATGACT TTAA TM I

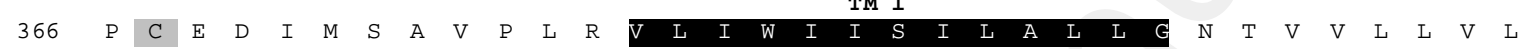
1301 CCCCTGTGAGGATATCATGTCCGCCGTCCCCCTGCGG GTCCTCATCTGGATCATCTCCATCCTCGCACT GC TGGGGAACACAGT GG TAC TTCTGGTCTTA TM II

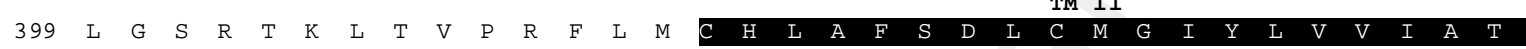
1401 TTAGGCAGCCGCACCAAAC TGACT GTTCCCCGTT TCC TCATG TGCCACT TGGCCTTT TC TGACCTC TGCAT GGGCA TCTACCTGGTAGTCA TAGCAACTG TM III

$\begin{array}{lllllllllllllllllllllllll}432 & V & D & M & \text { I } & T & Q & G & Q & Y & Y & N & H & A & I & D & W & Q & T & G & L & G & C & S\end{array}$ $\mathrm{V}$ F

1501 TAGACATGCTCACTCAAGGCCAGTACTACAACCACGCCA TAGACTGGCAGACGGGCC TCGGC TGCAGTGTT GCGGGCTTCT TCACGGTGTT TGCCAGTGA

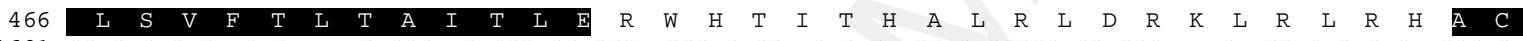
1601 GCTGTCAGTGTTCACATTAACA GCGATCACCCTGGAGCGTTGGCACACCATCACACA TGCTCTGCGGCTCGACCGTAAACT TCGTC TGA GACATGCCTGT TM IV

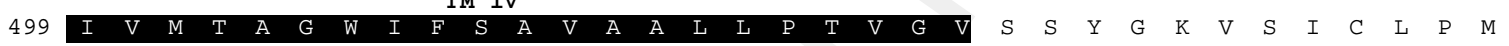
1701 ATTGTCATGACAGCAGGGTGGATCTTCTCCGCCGTAGCTGCT TTGCT TCCCACAGTCGGAGTCAGCAGCTACGGCAAGG TGAGTATCTG TC TGCCCATGG

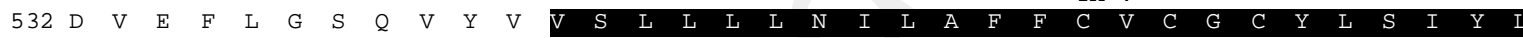
1801 ACGTGGAGT TTCTGGGGTCTCAGGTCTATGTGGTGTCACTTCTCCTCCTCAACATCCTGGCT TTCT TCT GCGTGTGCGGCTGTTACCTCAGCATCTACC

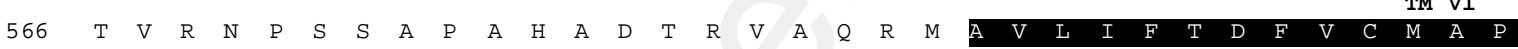
1901 GACCGTCCGCAACCCCTCGTCAGCGCCGGCCCACGCCGACACACGTGTGGCCCAACGCA TGGCAGTCCTCATCT TCACCGACTT TGTCTGCATGGCTCC

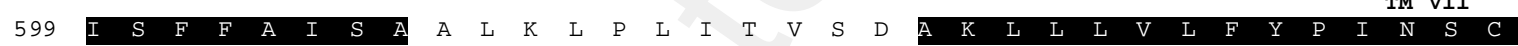
2001 ATCTCCT TCTTTGCCATCTCAGCAGCCCTCAAGC TCCCTCTCATCACAG TGT CA GAC GCCAAACTCCTGCTGGTCCTCT TC TACCCGATCAACTCC TGC T

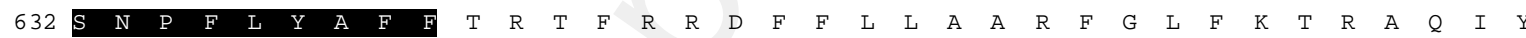
2101 CCAACCCCT TCCTGTACGCCTTCT TCACACGCACCTTCAGGCGGGAT TTCTT TC TCC TCGCAGC TCGCT TCGGCCT GTT TAAGACCCGAGCACAGATTTA

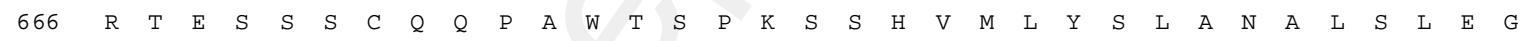
2201 CCGGACA GAGAGTTCCTCCTGTCAGCA GCCGGCGTGGACCTC TCCAAAGAGCAGCCACG TGATGCTGTACTCCT TGGCCAATGCAT TAAGTCTAGAAGGG 699 K $P$ E $\quad F \quad$ *

2301 AAACCAGAGTTCTGACT GT TAT TCAAAAGCAGATACAAACTT TT TGCTTAAT TT TGT TGGTT TTCATGTATCTC TGATA TGTTGCCAGTAT TTT TGGCCA 2401 GCACATCAGCTGCT GAT TC TTCAGACC TGACC TCAGACC TGCAACAACACAA GT ATCCA GTG TCCT TCT TAAACCA TGT GT GACAACTC TACTG TA TGTA 2501 CA GT GTG TA TAGAAAACCAAGT AA TAGCTACA GAACAAC TGCAGATACT TTGACCAAATCTA GG TCAAA TGGCT GT CCCAGATAAT TCC TT GTG TT TGT T 2601 TTAATTT GATTGGAACGCCAGA TGGGT GGAGT TTACT GCATAATAACAATTGAG TTCACAAGTAAA TGT AGGAGGA GTA TCAGA GGAGG TCAACTGACT T 2701 TTACTTTCA TGCAT TGTCT TAT AT AACATCCA TC TGG TG TCCCAAGA TAATGAAACAAGCTT AAAT ACT TT GAA TC TGT TTAAT AAAGG TT TGACACTCG 2801 GGATATCAGCATAT GAACGTCAAGAAA TCAACAT TCA TT TAACA TTCAACGTCA TGA TT GAA TGATATTCA TTAAGAAGCACACCGCAGGGACT TACTGT 2901 TTAATAATCTCCTCATACACCGTCTGCTGTAGCTCTACA TCCCTCCACA TCCCTCTTACCCTTCAGTGTCCATA TT TTT TTAATGAAGGACGTGTAATTA 3001 TCTT TGTAATGTAA TTA GG TTG TG TAAAT GAAAGTAC CACTGTT TTGTATATGT GTGTT TTGTACA GAA TA TATCT TTGAGATGTAATT TCATG TCATT T 3101 ATAAATT TG TTTAT TCAAAAAAAAAAAAAAAAAA 
Hum -------MALLLVSLLAF LSLGSGCHHRICHCSNRVF LCQESK---------VTEIPSDLPRNAIELRFVLTKLRVIQKGAF SGFGDLEKI Sbs MMMVMILIMLMILMIKTATASVPGPEMDVKPGVETS-LAKRTLSFCYQLKFGVTEIPSSISSNTTCLEVKQTEIVVIPQGALNSLQHLRKI

$\mathrm{Sb}$-MMAMILIMVTIVMIKMAGASAPDAETDVKP GADESVLAKRTLS ICNQLPPEVTEIPSNISSDTECLEVKQTQIGVIPRGAVHRLQHLRIL $\mathrm{T}$ il MMLVMTLMMLLIVT IKMAAASAHGSEMD IRP GF HPS-LAKQTSCLSYQVMFGVTAFP SNIS-NAQCLEVKQTQIRE IQQGTLSSLQHLMEL As -MMKMKKIMKMLLCVLGCVSMSQAEVAMVNSGTTFTYLCMGNT---------ITHMP TH IPKNTTDLEFKQTH IRVFPQEAFTNLQQLTAI Ats -MMKMKKIMKMLLCVLGCVCVSOAEVAMVNSGTTFTYLCMGNT--_------ITHMPTHIPKNTTNLEFKOTH IRVFPREAFTNLLOLTAI Rtr -MMKMKKIMKMLLCMLGCVCVSQAEVAMVNSGTTFTYLCMGNT---------ITHMP THIPKNT TDLEFKQTHIRVFPREAFTNLQQLTAI Z bf MVLSMMLCF ILGCS IANTEDTLAASQFCAFNGSTRSF ICLGNK---------VHEIPRRIPTNT TFVEIKLTQISVFRRAALSELHELKRI AC -----MLRYILSWLVMHTGNMF LGSYACLASGTTRSFLCLGSK--------VHQMP HH IP INT TYVE I KLTQI I IFPYRAMSSLHDLKRI C C -----MMCF I LSWLMMHAGNMCLGSYACLANGTTRSF LCLGSK---------VHQMPYH IP KNTTYVE I KLTRI IMLP SRAMS SLHDLKRI

-

Hum EISQNDVLEVI---------------------EADVFSNLPKLHEIRIEKANNLLY INPEAFQNLPNLQYLLISNTGIKHLPDVHKI 141 SbS TIWENDKLESINEFAFASLSQLTDIFISGNVALKNIGAFAFSDLPELTEITITKSKHLTHINPDAFKDIVKLKYLTIANTGLRLFPDFTKI 181

$\mathrm{Sb}$ IISKNEVLES I GAFAVAGLPQITNIFISENAELAS I GAFAFSDLPELTEMT ITKSKHLRH I HPDAFRNIVKLRVLI ISNTGLRMFPDFTKI 181

Til TISENDLLESIGAFAFSGLPHLTKILISKNAALRNIGAFVFSNLPELSEI I TTKSKHLSFIHPDAFRNMARLRFLTISNTGLRIFPDFSKI 180 AS VLTENGMLESI-------------------GAFAFANLPRLTEITITKSKHLVI IHHQAFIGLPKLSHLTICNTGLRVLPNFSRI 147 Ats VLTENGMLESI---------------------GAFAFANLPRLTEITITKSKHLVVIHHQAFMGLPKLSHLT ICNTGLRVLPNFSRI 147 Rtr VLTENGMLESI-----------------------GAFAFANLPRLTEITITKSKHLVI IHHQAF IGLPKLSHLTICNTGLRVLPNFSRI 147 Zbf VVSENGALERI------------------------EALAFFNLTELEEITITKSKNLV-MHKDAFWRLPKLRYLTISNTGLKILPDFSQI 147 AC MVSENGALQRI---------------------EAYAFANLTILEEITITKSKNLVSMDRDTFWGLPKLRYLTISNTGLTVLPDFSKV 143 CC LVSENGVLQRI--------------------EAYAFANLTKLEEITITKSKNLVCMDRHTFWGLPKLRYLTISNTGLTVLPDFSKV 143

Hum HSLQ-KVLLDIQDNINIHTIERNSFVGLSFESV-ILWLNKNGIQEIHNCAFNGTQLDELNLSDNNNLEELPNDVFHGASGPVILDISRTRI 230 SbS HSTG-LLLFDLHDNSHIERVPANAFKGLCTOTIPEIRLTRNGIKEVASDAFNGTKMHRLFLRGNKOLTHINPNAFVGSSELVVLDISOTAL 271 $\mathrm{Sb}$ HSTAPDFLFGLQENSHIERVPVNAFRGLCTQT ISEIRLTRNGIKEVASDAFNGTKMHRLRLSGNQQLTHINPNAFVGSSELVVLDISHTAL 272 Til HSTA-CFLLDLQDNSHIKRVPANAFRGLCTQTFAEIRLTRNGIKEVASDAFNGTKMHRLFLGGNRQLTHISPNAFVGSSELVVLDVSETAL 270 As HSAAMTFLLDLQDNVHIVIIP SNAFLGLTTNT IDELRLTKNGISEVESHAFNGTKIHKLYLMGNLQLSHMHNNSF KGAEGPGFLDISRTAL 238 Ats HSTALTFLLDLQDNVHIVIIP SNAFLGLTTNT IDELRLTKNG ISEVESHAFNGTKIHKLFLMGNLQLSHMHNNSFKGAEGPGFLDISRTAL 238 Rtr HSAALTFLLDLODNVH IVIIPSNAFLGLTTNTIDELRLTKNG ISEVESHAFNGTKIHKLF LMGNLOLSHMHNNSFKGAEGPGFLDISRTAL 238 Zbf NSAALEFLFDLQDNMHIERIP SNAFLGLTNATITELRLTKNG IREIDSHAFNGTKIGKLFLMGNQQLNH I HSYAFKGAEGPVVLDISRTAV 238 AC QSAAFEFLFDLEDNMHIEVI HSNAFAGLTSGTITELRLTKNGITEVERNAFNGTKMEKLFLMGNQQLKRIDNHAFLGAEGP LVLDISRTAI 234 CC QSAAFEFLFDLEDNMHIEVIP SNAFAGLTSGTITELRLTKNGITEVDRNAFNGTKIEKLFLMGNQQLKRI HNYAELGAEGPLVLDISRTAI 234

Hum HSLPSYGLENLKKLRARSTYNLKKLPTLEKLVALMEASLTYPSHCCAFANWRRQISELHP-İCNKSILRQEVDYMTQTRGQRSSLAEDNES 320 SbS SSLPDYILGGLQKLIAESAPNLKELPPLELFTKLHQANLTYSSHCCAFHNIHRNRSKWNS-LCSHPDAQGNLHFY-------------- 345

$\mathrm{Sb}$ SSLPENILGGLOKLMAESVFRLKELPPLOLFNKLOEVHLTYP SHCCAFHNVHRNRS SWNALLCSHPDAPGMPNFY---------------- 347

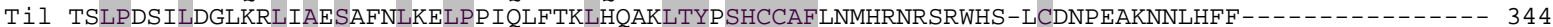

AS SSLPESVLGEVEHLSAVSVF SLRTLPPLSLFTKLRQANLTYP SHCCAF HKHQRNRTFRMT SACF KP GAQNNLHFF--------------- 313

Ats SSLPESVLGEVEHLSAVSVF SLRALPPLSLFTKLRQANLTYPSHCCAFHKHQRNRTFRMNSACFKP GAQDNLHFF-------_----- 313

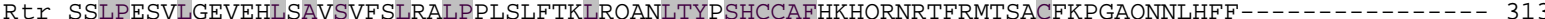

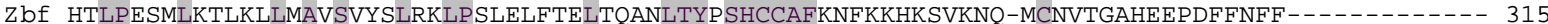

Ac SSLPENMLRRLKLLIATSVYSLRWLPNLEIFAELTQANLTYP SHCCAFKNFKKNKLEKNH-LCNVSTIRNQEPYF--F----------- 309

CC SSLPENMLRRLKLLIATSVYSLRWLPNLEIFTELTQANLTYPSHCCAFKNFKKNKSEKNR-LCNDST IRNQEPYF--F----------- 309

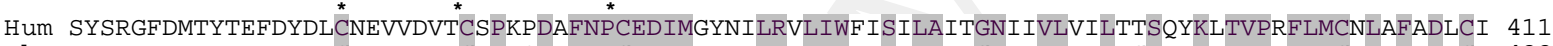
Sbs ----------RDYCSNSTSIICTPTQDDFNPCEDIMSAVPLRVLIWIISILALLGNTVVLLVLLGSRTKLTVPRFLMCHLAFSDLCM 422

$\mathrm{Sb}------------K D H C S N S T$ I I ICTP TODEFNPCED IMSAVP LRI L IWI I S I LALLGNAAVLLVLLGSRCKLTVPRF LMCHLAF SDLCM 424 Til --_--_--_----REYCSNSTNITCSPAPDDFNPCEDIMSATP LRILIWI ISVLALLGNAVVLLVLLGSRYKLTVPRFLMCHLAFADLCM 421 As -------MDFCLNWT SVACSPAPDAFNPCED IMGSAP LRVLIWI I SVLALLGNT IVLLVLLGSRAKMTVPRF LMCHLSFADLCM 390 Ats ------------MDFCLNWT SVACSPAPDAFNPCED IMGSAP LRVLIWI I SVLALLGNT IVLLVLLGSRAKMTVPRF LMCHLSFADLCM 390 Rtr ----------MDFCLNWT SVACSPAPDAFNPCED IMGSAP LRVL IWIT SVLALLGNT IVLLVLLGSRAKMTVPRF LMCHLSFADLCM 390 Z bf -------NDHCKDVIEVTCYP TPDAFNPCED IMGF TF LRVLIWF I SVLAIVGNTVVLLVLLTSRYKLTVPRF LMCHLAFADLCM 392 AC --_--_--_---EEHCKDVIEVSCYPEPDAFNPCED IMGFTF LRVLIWF I SVLAVLGNFTVLLVLLSSHTKLTVPKFLMCHLAFADFCM 386 CC ------------EEHCKDVIEVRCYPEPDAFNPCED IMGF TFLRVLIWF I SVLAVLGNFTVLLVLLSSRTKLTVPKF LMCHLAFADFCM 386 
1 CACT TGATGAGAAGTTGAGTAACAGGTGGCTGACATT GTCCTCCGCACGGCT TCGATGACGATCTGCTGCGGTTGCAGCAAAAGAGACT TTAAAGAAGGG $\begin{array}{lllllllllllllll}M & \boldsymbol{W} & T & S & L & P & A & L & L & F & L & S & V & L\end{array}$ 101 CCAGAGA TCTTAATGCGCAGCGCTCAGCGGGCATCCCGGCTTCTGTGCGTTTTACAGAATGTGGACCTCGCTGCCGGCGCTCTTGT TCCTGTCTGTTTTG

$\begin{array}{llllllllllllllllllllllllllllllllllllllll}15 & \boldsymbol{G} & \boldsymbol{F} & \boldsymbol{Y} & \boldsymbol{G} & \boldsymbol{C} & \boldsymbol{K} & \boldsymbol{C} & \mathrm{A} & \mathrm{P} & \mathrm{G} & \mathrm{F} & \mathrm{G} & \mathrm{C} & \mathrm{P} & \mathrm{R} & \mathrm{I} & \mathrm{C} & \mathrm{R} & \mathrm{C} & \mathrm{F} & \mathrm{S} & \mathrm{N} & \mathrm{T} & \mathrm{I} & \mathrm{R} & \mathrm{C} & \mathrm{N} & \mathrm{N} & \mathrm{V} & \mathrm{T} & \mathrm{Q} & \mathrm{G} & \mathrm{S}\end{array}$ 201 GGCTTCTACGGA TGCAAGT GCGCTCCGGGTTTCGGCT GTCCGAG GATCTGCCGC TGT TTCTCCAACACAATCAGAT GCAACAAT GTAACTCAAGGG TCGG

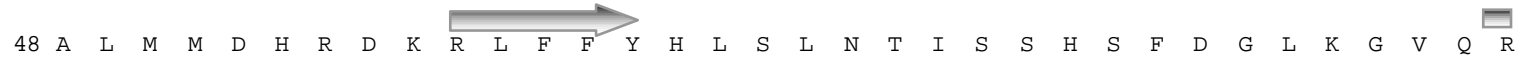
301 CGCTGATGATGGATCACAGAGA TAAAA GACTGTTTTTCTATCATTTGTCTTT GAACACCATT TCCAGCCATTCT TT TGATGGTT TAAAAGGAGTCCAGAG

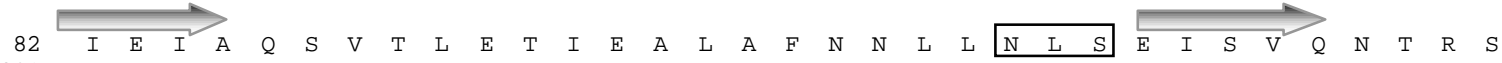
401 GATTGAGAT TGCTCAGA GT GTAACCCT GGAAACCATT GA GGCAT TAGCCTTTAA TAACCTTCTCAACCTCTCTGAAATCTCAGTCCAGAACACGAGGAGT

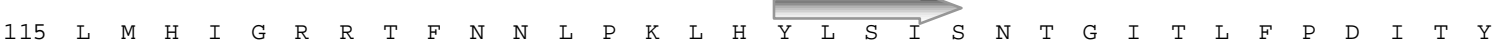
501 CTGATGCACATT GGCAGAAGGACATTCAATAACCTCCCCAAACTACATTACT TGAGCATCTCAAATACT GGGATAACCCTT TTCCCTGACA TTACATATA

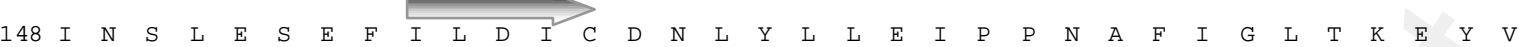
601 TCAATTCTCTTGAATCCGAGTT TATCT TGGATATATGTGATAACCTGTATCTACTGGAAATACCTCCTAACGCT TTCATCGGAC TGACAAAGGAGTATGT

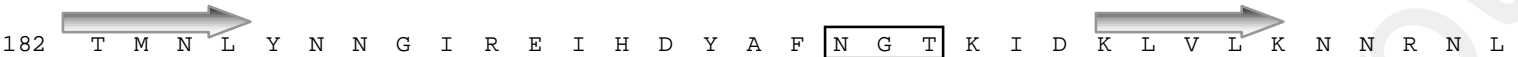
701 TACAATGAACCTGTATAACAACGGCATCAGAGAAATACACGACTACGCCTTCAACGGGACAAAGATAGA TAAGC TGGTATTAAA GAATAATCGAAACCTC

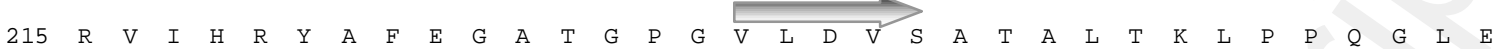
801 AGAGTGA TCCACAGATATGCTT TCGAAGGAGCCACAGGACCT GGAGTCT TGGACGTT TC TGCGACAGCT CTCACAAAGT TGCCACCGCAGGGACTGGAGT

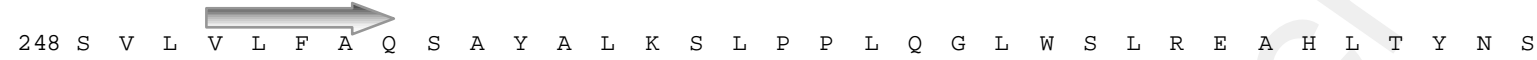
901 CAGTTCTGGTGT TGTTTGCTCAGTCAGCATATGCCTTGAAGA GTCTGCC TCCTCTGCAGGGACTGTGGAGCCTGCGAGAGGCCCATCTCACCTACAACAG

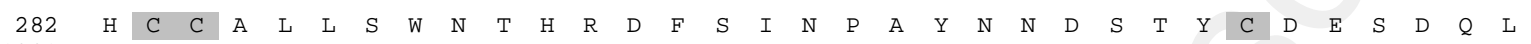
1001 TCACTGT TGTGCGC TGCTGAGC TGGAACACCCACAGG GACTT TTCCATT AATCC TGCATATAATAA TGACTCTACT TAT TGTGA TGAGA GT GACCAATTA

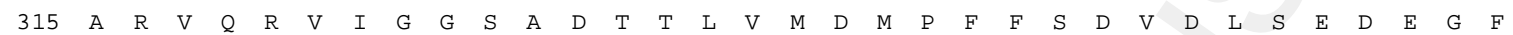
1101 GCAAGGGTTCAGCGTGT GATTGGAGGT TCAGCAGACACGACTCTAGT TATGGATATGCCATT TT TT TCA GACGT TGATT TA TCT GAGGACGAGGGCTTTG

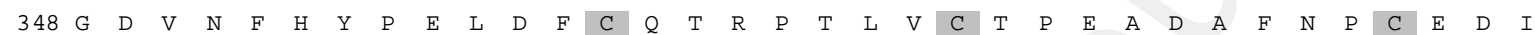
1201 GAGACGT GAATT TCCACTATCCAGAGC TGGACTTCTG TCAGACCCGACCAAC TT TGG TT TGCACACCTGAAGCA GA TGC TT TCAATCCC TG TGAGGACAT TM I

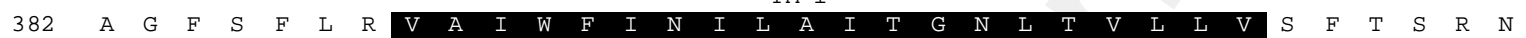

1301 TGCAGGT TTCAGTT TTCTCAGA GTAGCCATTTGGTTTATCAACA TACTGGCCATCACAGGCAACCTGACAGTCCTCCTAGTCTCCT TCACCAGCCGCAAC

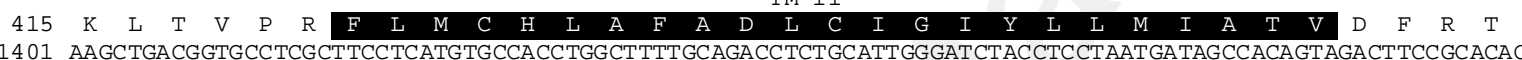
TM II

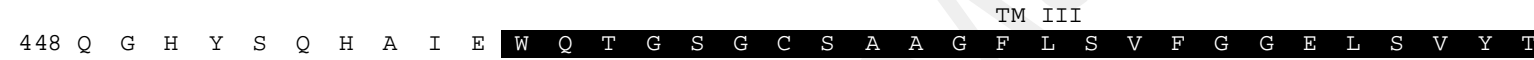
1501 AGGGCCACTACA GT CAGCATGC TA TTGAATGGCAAACAGGGTCTGGCTGTAGTGCTGCAGGCTTCCTGTCTGTGTT TGG TGGGGAGCTGTCAGTCTACAC

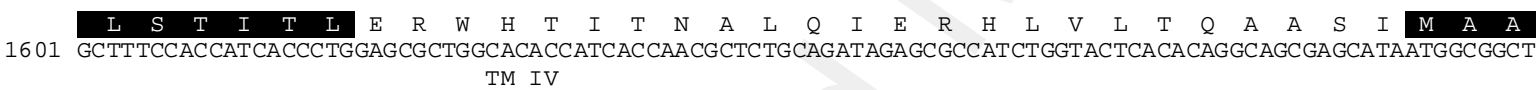

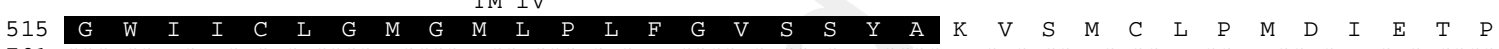

1701 GGGTGGATCATCTGTCTGGGGATGGGGATGCTGCCTC TGTTTGGCGT GAGCAGT TACGCCAAAGTCAGCATGTGCT TACCAATGGACATAGAGACCCCCC TM V

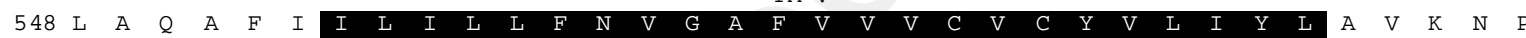
1801 TGGCTCAGGCCT TCATCATACTCA TCC TGCTCTTCAACGTGGGCGCCTT TGT TG TTG TG TGT GT TT GTTACGTGCTGATCTATCTGGCT GT GAAAAACCC

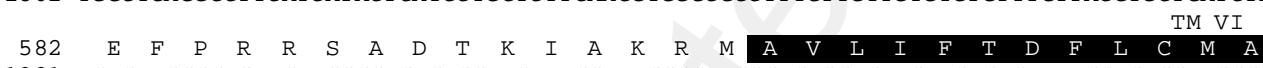

1901 AGAGTTCCCCAGAAGAAGCGCTGACACCAAGATT

\begin{tabular}{l} 
TM VII \\
\hline
\end{tabular}

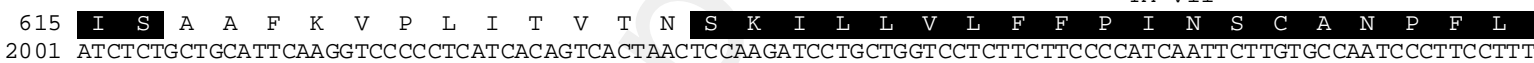

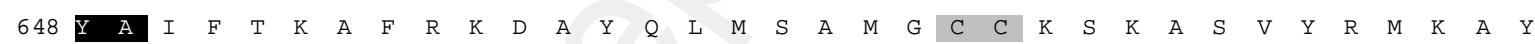
2101 ACGCTATCT TCACCAAGGC TTT TAGAAAGGACGCATATCAGCTCATGAGTGCCATGGGATGCTGTAAAAGCAAGGCCAGTGTTTATCGCAT GAAGGCCTA

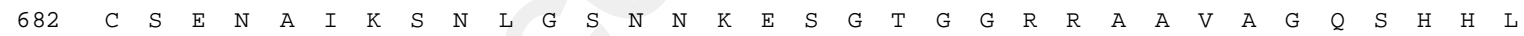
2201 CTGCTCCGAAAA TGCAA TCAAGAGCAACC TGGGA TCCAA TAA TAAAGAA TCA GGCACAG GAGGGCGGCGGGCTGCGGTGGCAGGGCAGA GCCATCACCTG

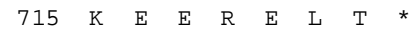

2301 AAAGAGGAGAGGGAGCTCACCT GAAATAAAAA GATTCAAAAG TC TTT TAATTGGACAAT TGG TCAAGAGAAACT AAGGAAAAAAACAAC TCATGCT GGA T 2401 TTGGAGGAAATT AC TCT AACAT GT TGACA TTGAT GGCATATT TT AATCT GCACT GTT GGAGA TA TT TGT AT TAGAAAGT ATAAGAAAATCT TAT TGCCT T 2501 TTCCAAA TCTGATA TCA GT TCAACCCAAT AAAAAAATAGTTT TT TTGTT GAC TGGTTAT GACAGGAAAA GTAAAAC GAA TAACACT GAT GA TCGCTCTGT 2601 TGTT TCA GG TCCACCTG TAGTT TCATA TG TCAAAATG TC TTG TAAATATACA GAAGAAA GCTCT GGAAACA GCT AC TAAAT GGACC TTTAT GGACC TTTG 2701 TTGTATT GTCAGCTATGAACTG TCATATCTCA GTATT TAATGGGATGACCTAAACGAACAAGAAGACTT TAAAAAGCTGCCAAAAAACT GAAAT TT GAAA 2801 CATCACCTGTTCAGATC TACTGAT TGTAT GACACAGT GT TAAAC TCCTTGTGGT GAGAC TGA GT GATCT GC TTCATCCTAGCTTCA TCTCCAAAGT TCA T 2901 CTGAATGAGAATCAAACCAGAGCT GTCAGTTTATCTCAATGT TATTGATGTATG TGAAATAAAT TGTCCGC TTCAT TCTGGGTGTGAAATT AAGAACATC 3001 TATAGCCATGGT TAGTATT TAAAGGTTATAGCCTATAGT TGACCACGTGGTGGAGTA GT TGGGAGGAAAAC TTC TACACCACTTGAGTT TT TGT TGTTCT 3101 TTTGGCCTAAGGGT TTT TGGGATTATGTAATTCAAAA TAAAA GACTTCACCTACAAAAAAAAAAAAAAAAAA 


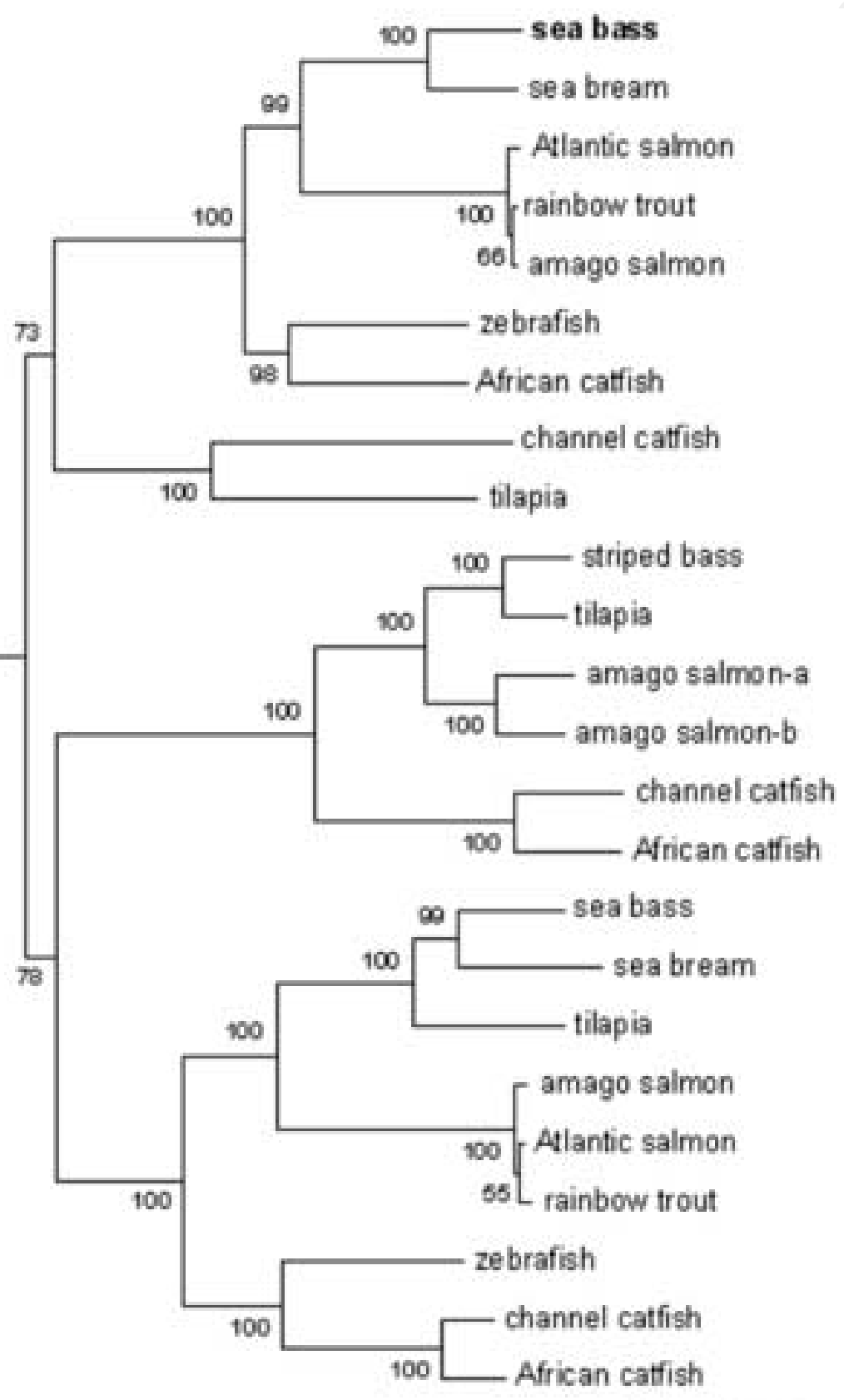

LHRs

TSHRs

FSHRs

Caenorhabditis elegans LGR

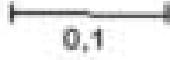


A
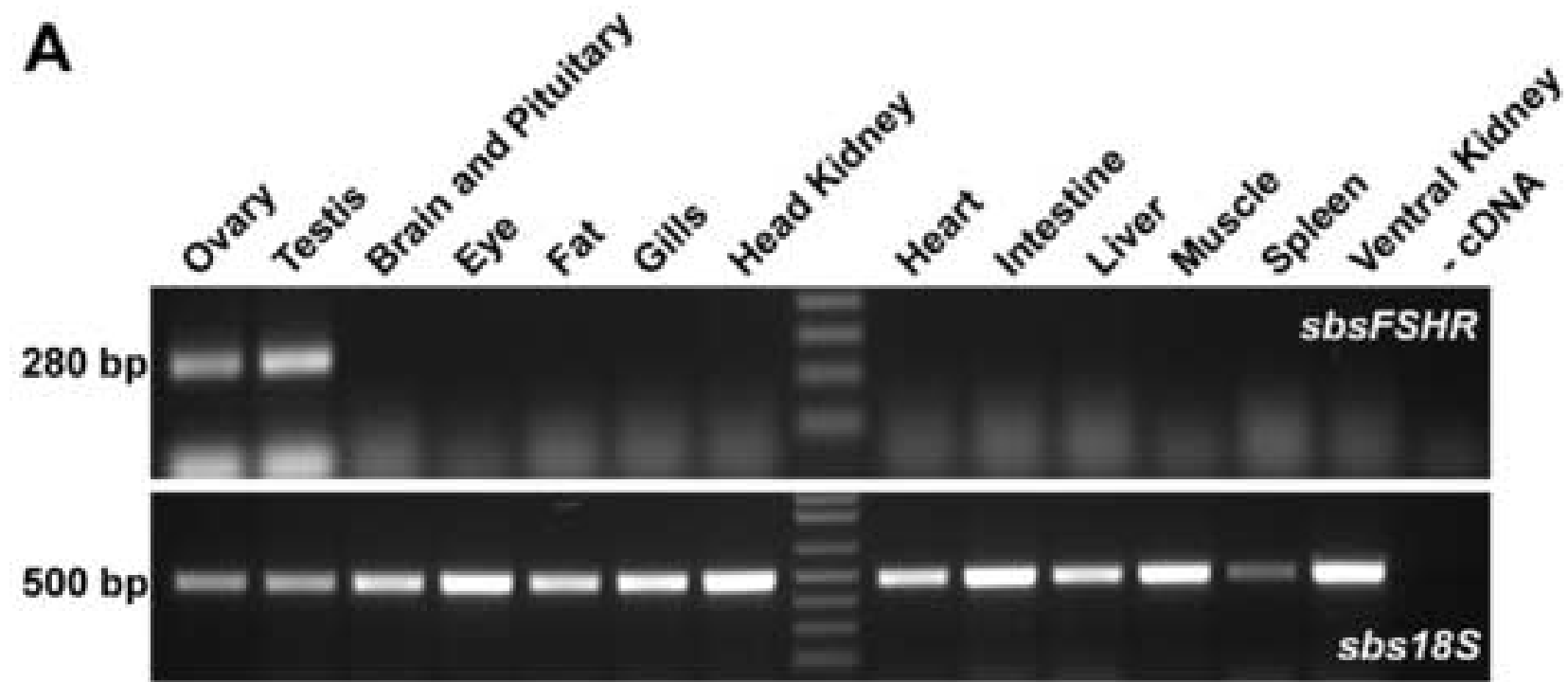

B

400 bp

300 bp

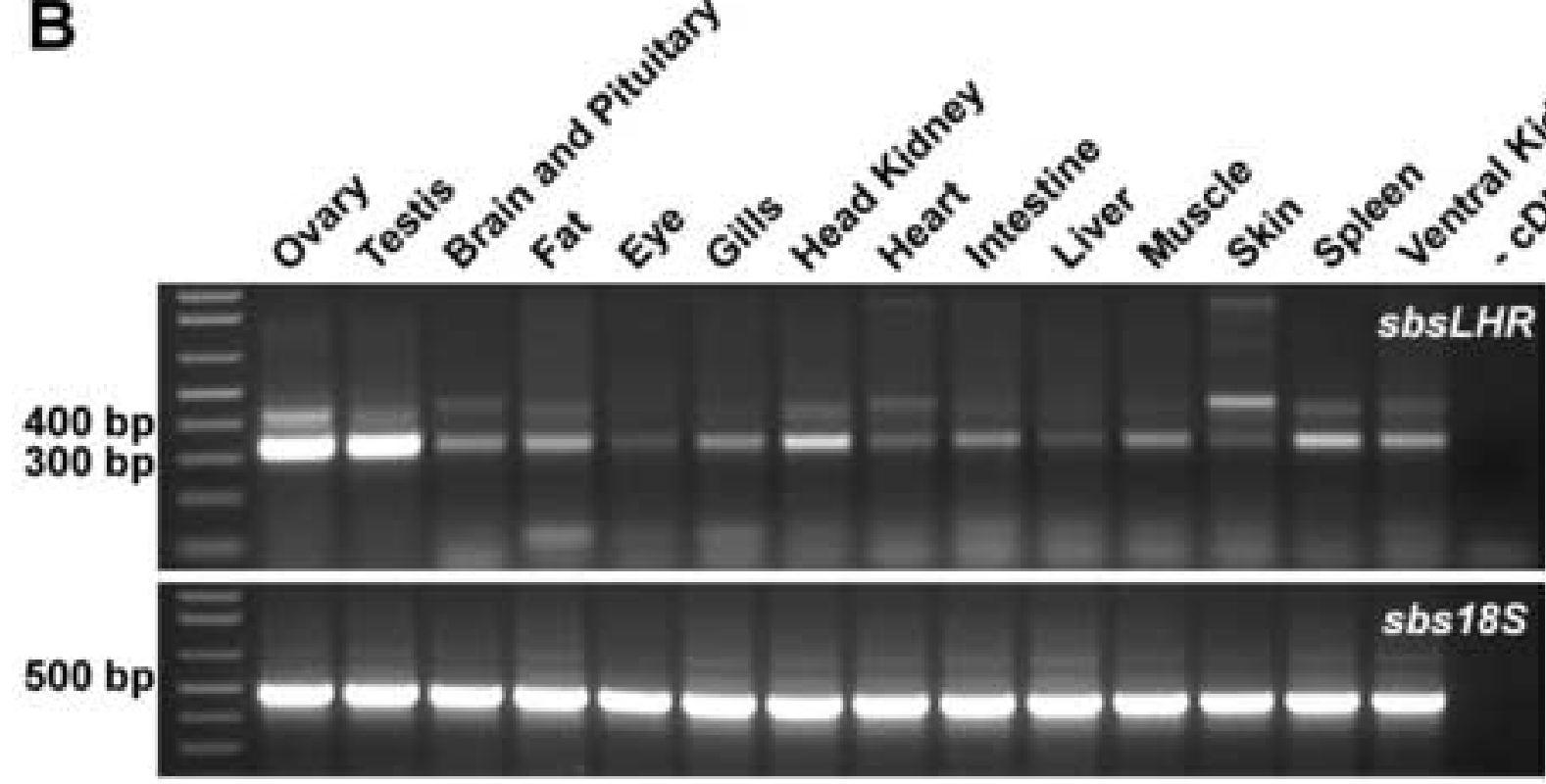

C

sbsFSHR

sbsLHR

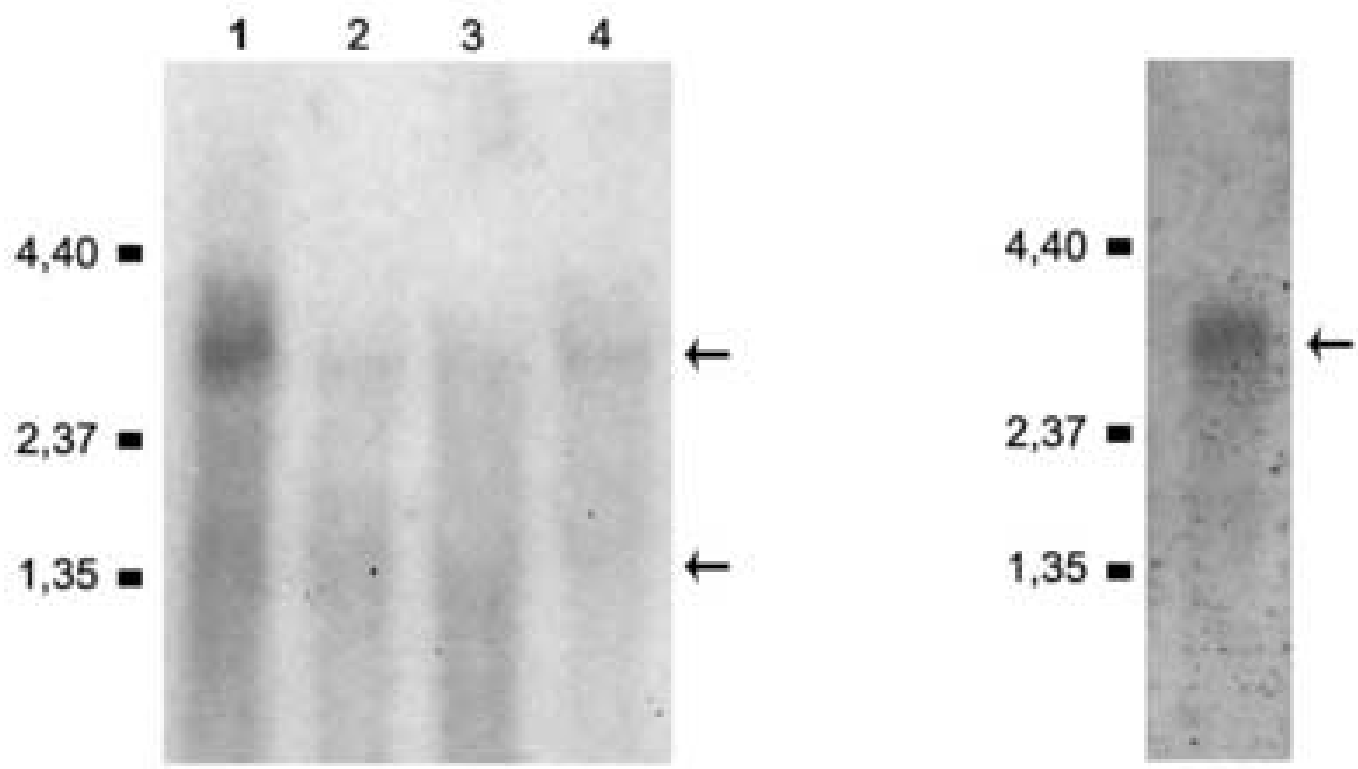




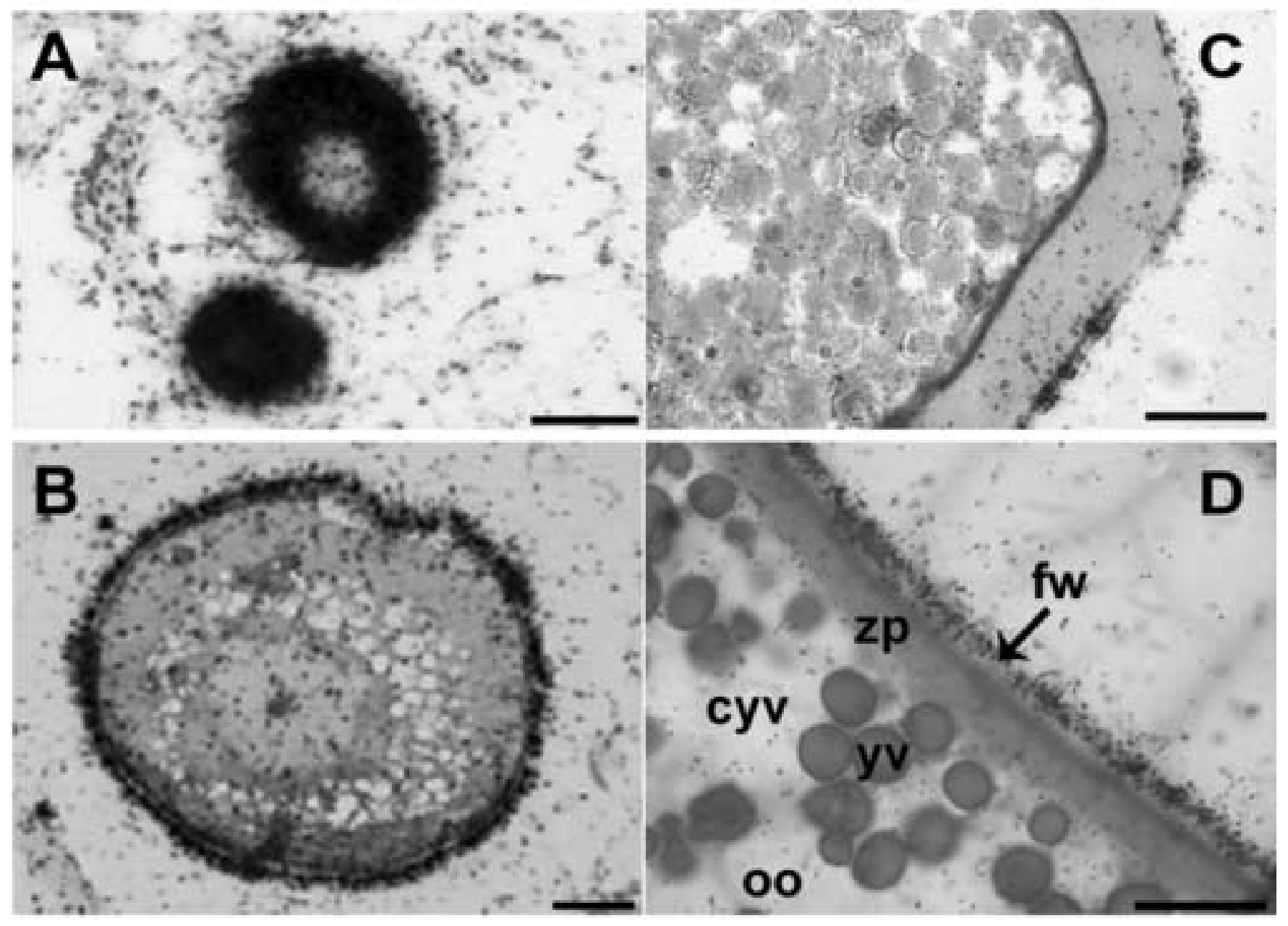


A

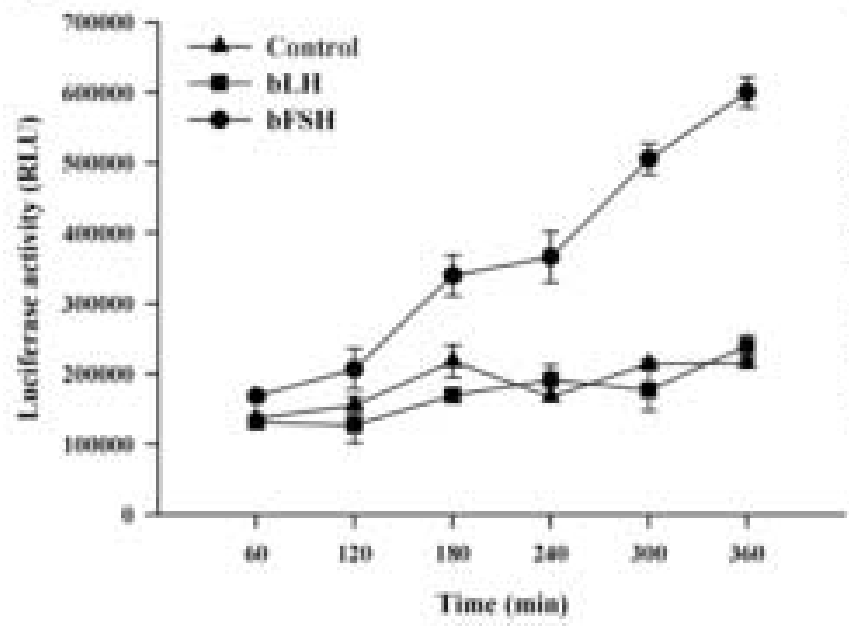

B

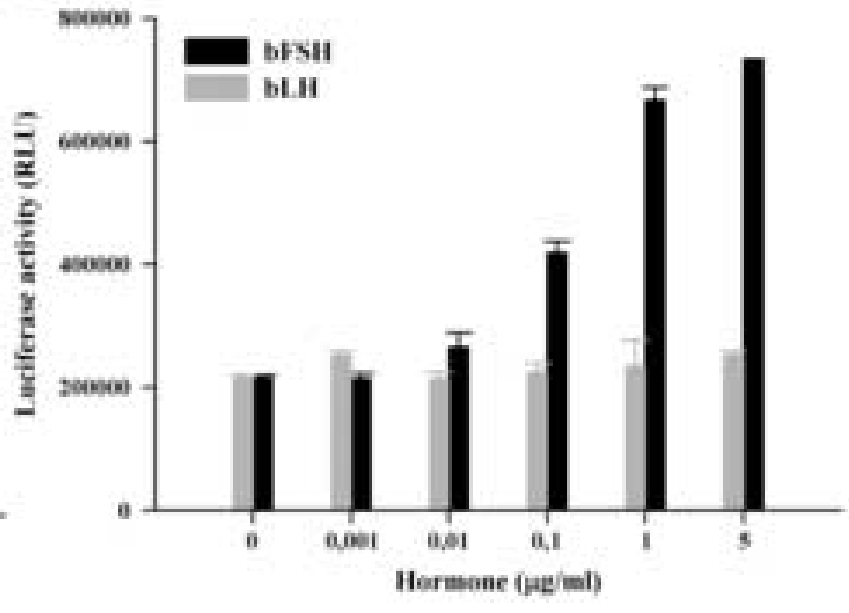



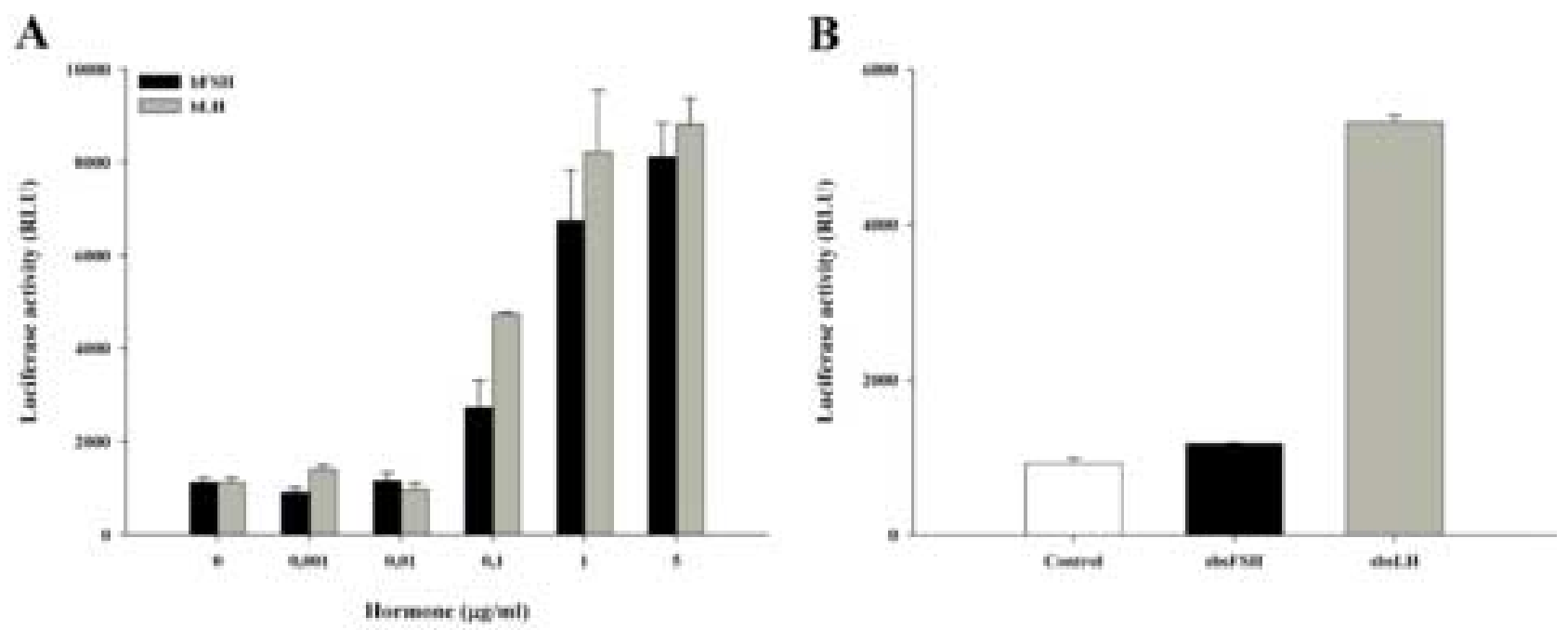